\title{
Numerical Investigation of Room Temperature Magnetic Refrigerators Using Microchannel Regenerators
}

\author{
Muhammad Sajid Kamran ${ }^{\mathrm{a}, \mathrm{b}}$, Jie Sun ${ }^{\mathrm{a}, \mathrm{c}}$, Yong Bai Tang ${ }^{\mathrm{a}, \mathrm{d}}$, Yong Gui Chen ${ }^{\mathrm{d}}$, Jiong Hong $\mathrm{Wu}^{\mathrm{e}}$, Hua Sheng
} Wang $^{\mathrm{a}^{*}}$

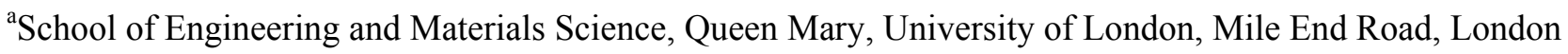
E1 4NS, UK

${ }^{\mathrm{b}}$ Department of Mechanical Engineering, University of Engineering and Technology, Lahore 54890, Pakistan ${ }^{c}$ Institute of Engineering Thermophysics, Chinese Academy of Sciences, Beijing 100190, China

${ }^{\mathrm{d}}$ School of Materials Science and Engineering, Sichuan University, Chengdu 610065, China

${ }^{\text {e}}$ School of Mechanical and Automotive Engineering, South China University of Technology, Guangzhou 510640, China

\begin{abstract}
The paper reports numerical investigation of room temperature, active magnetocaloric regeneration (AMR) refrigerators/heat pumps using microchannel regenerator. The microchannel regenerators are made of a magnetocaloric material (MCM), Gd, with diameter of the circular channels ranging from $0.7 \mathrm{~mm}$ to 2.0 $\mathrm{mm}$. Water, the working fluid, oscillates in the regenerator loop driven by two piston-cylinder displacers operating in a range of mass flow rates. Three dimensional conjugated fluid convection and conduction heat transfer in the microchannel regenerator was modeled and numerically simulated using ANSYS Fluent. The magnetocaloric effect (MCE) was incorporated into conservation of energy using a discrete method to simulate the magnetization and demagnetization of the MCM. The hot and cold end heat exchangers were treated with the $\varepsilon-N T U$ method. Effects of utilization and porosity of the microchannel regenerator and cycle frequency on the cooling capacity and temperature span were examined. When the utilization, porosity and cycle frequency are $0.2,0.5$ and $5.0 \mathrm{~Hz}$, respectively, the predicted maximum cooling capacity was about 22 $\mathrm{W}$ for a $0.8 \mathrm{~T}$ variation in intensity of magnetic field. The effects of magnetic field intensity, reservoir temperature span and flow rate profile on the refrigeration performance were also investigated. The performance of the microchannel regenerator is compared with that of the parallel plate regenerator for the no-load temperature span, cooling capacity and pumping power. Under specific geometric and operating conditions, the microchannel regenerator shows better performance than the parallel-plate one.
\end{abstract}

Key words: Magnetic refrigeration, Microchannel regenerator, Numerical modelling, Magnetocaloric material, Air conditioning, Heat transfer enhancement

Corresponding author: h.s.wang@gmul.ac.uk 


\section{Introduction}

The demand for energy and environment protection has led to a large global effort to find new refrigeration technologies in addition to developing and improving existing ones. Magnetocaloric refrigeration/heating is an environmentally friendly, step-change technology with potential to replace conventional vapour-compression refrigeration [1]. In recent years, a number of magnetic refrigeration prototypes have been built with different design configurations, magnetocaloric materials (MCMs) and regenerator geometries. The noteworthy prototypes amongst them are the device built by Astronautics Laboratory, USA [2-4], the Chubu Electric and Toshiba device[5], the institute of technology/Chubu, Japan [6], the Nanjing University device, China [7], a reciprocating and a rotary prototype developed at Riso Lab [8-13], a reciprocating prototype at POLO Research Laboratories [14], the University of Victoria's prototypes [15-19], a rotary system developed by Kitanovski et al. [20], the prototype developed by University of Ljubljana, Slovenia [21-23], the rotary prototype developed at University of Salerno, Italy [24] as well as the reciprocating prototypes built by Tagliafico et al. [25], Gatti et al. [26], Legait et al. [27], Park et al. [28], Kotani et al. [29] and Czernuszewicz et al. [30]. Various review articles such as [1, 31-33] have summarized the performance and key challenges to the technology. For instance, Yu et al. [1] reviewed a number of prototypes built till 2010. A summary of the prototype magnetic refrigerators built by various research teams is presented in Table 1. In these prototypes, Gd and Gd-based alloys were the most commonly employed MCMs, however alloys of LaFeCoSi with varying Curie temperatures were also used [23, 27]. The regenerator geometries included particles (spherical) [2, $3,5-11,28]$, flat plates $[8,14,25,27]$ and honeycomb structure [20]. It can also be observed that the specific cooling capacity and the corresponding temperature span for these prototypes is insufficient to replace the conentinal vapor compression. The compromised performance of the system may be attritubed to several factors such as relatively smaller magnetic field variations produced by permananet magnet assemblies (upto 1.5 T), smaller magnetocaloric effect (MCE) per unit field variation $(1.5-2 \mathrm{~K} / \mathrm{T})$, limited temperarture gradient across two ends of the regenerator and large pressue drop in the regenerator. Consequently, these factors add to the per unit cost of refrigeration produced and make it much higher than vapor compression system [20,34] and thus have become the major obstacles in the commercialisation of the technology.

To build a magnetic refrigeration prototype, many researchers conducted numerical modelling of the system (focused on regenerators) to predict the performance and optimize design under various operating conditions, the geometric configurations and dimensions of the regenerator. In the last decade, a number of 1D and 2D numerical models have been developed. For example, Siddikov et al. [35], Dikeos et al. [36] and Engelbrecht et al. [37, 38] developed 1D models considering all the major terms e.g. temperature dependence of fluid properties, built-in MCE, $T$ and $B$ dependent 
heat capacity of MCM, longitudinal thermal conduction, pressure drop and thermal dispersion. A numerical model for the packed bed regenerator using water-glycol and discrete MCE was developed by Aprea and Marino [39]. Tagliafico et al. [40] developed numerical model to investigate the effect of utilization, frequency and temperature span on the AMR performance. MCE was implemented as an instantaneous temperature change and effect of the axial conduction was also considered. Tusek et al. [21] developed a model for packed bed regenerator with water as HTF with constant properties. MCE was implemented as an instantaneous temperature change. Axial conduction, pressure drop and thermal dispersion were taken into consideration. Vuarnoz and Kawanami [41] developed a 1D model to evualuate the performance of AMR and optimize the design of thin-wire based regenerator of Gd with water as HTF. The pressure drop, coefficient of performance (COP) and refrigeration capacity of the system were evaluated. Plaznik et al. [42] have numerically simulated and experimentally validated the system performance for three different operating cycles for packed bed and parallel-plate regenerators. Silva et al. [43, 44] have numerically (1D model) tested the performance of a solid-state (no working fluid) magnetic refrigerator. Their proposed model considered employing MCMs with magnetic field dependent thermal conductivities. Vuarnoz et al. [45] developed a theoretical model to explore the potential of magnetocaloric energy conversion system in waste heat recovery systems. A theoretical approach to reveal the irreversibilities in magnetic Brayton cycle and to formulate cooling capacity and COP of a magnetocaloric system was employed Xia et al. [46]. Lozano et al. [11] developed 1D model for a rotary experimental setup employing spherical Gd particles and magnetic field intensity of $1.24 \mathrm{~T}$. Other recently developed 1D models such as Burdyny et al. [47], Chiba et al. [48], Govindaraju et al. [49], Nikkola et al. [50], Eriksen et al. [51] are listed in Table 2.

Petersen et al. [52] developed a 2D model for the parallel-plate regenerator, with water as HTF and temperature and field dependent heat capacity of the MCM. Nielsen et al. [53] extended the model developed by Petersen et al. [52] by taking into account the parasitic heat losses of system. They also conducted a parametric study to investigate the influence of various operating parameter on the performance of the AMR[54]. Nielsen et al. [55] have numerically investigated the performance dependence on demagnetizing fields for parallel-plate regenerators. Legait et al. [56] developed a 2D model using a commercial software Fluent. MCE was applied as constant value of $1.4 \mathrm{~K}$ which was added and subtracted from the solid zone temperature during the magnetization and demagnetization respectively. The model could predict results within 10\% accuracy. Liu and $\mathrm{Yu}$ [57] developed 2D numerical model for the packed bed regenerator. The model can predict internal temperature distribution within the regenerator, cooling power and the COP of the system. Oliveira et al. [58] developed a 2D hybrid model for parallel plate regenerator, in which the fluid flow equations were analytically solved while heat transfer equations were solved numerically using 
finite volume method and MCE was implemented as an instantaneous temperature change. Lionte et al. [59] developed a 2D numerical model for the parallel plate regenerator using built-in method for the implementation for the MCE. Lastly, a 3D simulation for packed bed regenerator was performed by Bouchard et al. [60] using discrete MCE method. A detailed review of the numerical models developed till 2011 is presented by Nielsen et al. [61].

A brief description of the numerical models is also presented in Table 2. The majority of the models developed are 1D. One major reason for the popularity of $1 \mathrm{D}$ models is their relatively small computational time requirement along with the acceptable accuracy. However, these models may lack the ability to capture thermal and flow characteristics in other two dimensions. Two dimensional models solve the governing equations in two spatial dimensions i.e. along the flow direction and perpendicular to the flow direction. The MCM regenerator plays a key role in the system performance of room temperature magnetic refrigerators. The regenerator geometries need to be investigated by building their $3 \mathrm{D}$ models to predict more realistic results. The latest advancements in the numerical schemes and the enhanced computational capability allow analysis of complex geometries. It can be seen in Table 2 that the numerical models have been built for various regenerator geometries e.g. packed-bed, parallel-plate and thin-wire based regenerator and the effect of various operating parameters on the performance have been investigated. The enhanced thermo-hydraulic properties (high heat transfer rate and low pressure drop) of regenerators can be achieved by the proper selection and optimisation of the working fluid, type of regenerators, their geometric configurations and dimensions. Microchannel heat exchangers have proved to be both compact and effective for both single-phase and two-phase flow heat transfer [62, 63]. As the literature survey unveils, so far no substantial experimental or numerical studies have been done to investigate the feasibility of microchannel regenerators for magnetic refrigerator except that Tura et al. [64] investigated the flow and heat transfer in a passive microchannel regenerator. In the present work, microchannel MCM regenerators are used and the performance of the refrigerators is numerically examined. The objective is to improve heat transfer, decrease pressure drop and enhance the performance of the refrigerator.

\section{Microchannel Regenerator Refrigerator}

A schematic of a, prototype, room temperature magnetic refrigerator/heat pump is shown in Fig. 1. The regenerator loop consists of microchannel regenerator, hot end heat exchanger (HHEX), cold end heat exchanger (CHEX) and displacer. The heating and cooling loops consist of the CHEX/HHEX and a reservoir, respectively. Magnetic field is provided via a C-shape assembly composed of two permanent magnets and a soft iron block connecting the two magnets. The permanent magnet assembly rests on a slider and transversely moves forwards and backwards 
relatively to the regenerator under the control of a pneumatic arm (see Fig. 1) to achieve the maximum and minimum magnetic field $B_{\max }$ and $B_{\min }$. The maximum intensity of the magnetic field of the present design is determined to be $0.8 \mathrm{~T}$ by using the finite element analysis. As shown in Fig. 2, the microchannel regenerator is made of $\mathrm{Gd}$, a magnetocaloric material (MCM), and has a number of circular cross-section channels of diameter $1.0 \mathrm{~mm}-2.0 \mathrm{~mm}$. A displacer comprising of two piston-cylinders makes the working fluid oscillate between the hot and cold ends periodically. The MCM regenerator is cooled down and heated up during magnetization and demagnetization processes, respectively.

\section{Physical model}

The dynamic working process of the refrigerator is simulated to predict and optimise the performance. The five main components of the magnetic refrigerator i.e. regenerator, permanent magnet assembly (magnetic field source), heat exchangers and displacer are modelled as shown in Fig. 3. The fluid flow and heat transfer through one channel are shown in Fig. 2(b). The magnetization and demagnetization occur in the regenerator when there is a relative motion between the magnet and regenerator. A positive volumetric energy source appears in MCM during magnetization and a negative one during demagnetization. MCM is periodically exposed to hot and cold fluid flows. The CHEX and HHEX are concentric tube heat exchangers. Water is used as the working fluid.

To simplify, the following assumptions and approximations are made: 1) Magnetic field is uniform in the regenerator and the demagnetizing field is neglected; 2) Thermal and magnetic hysteresis of MCM are negligible; 3) Properties of the MCM are independent of temperature and magnetic field intensity; 4) Flow is incompressible; 5) Thermophysical properties of the working fluid are taken to be constant; 6) Viscous dissipation is neglected; 7) Heat loss to the ambient is neglected; 8) There are no fluid leakages in loops; 9) The dead fluid volume inside the entire system is zero.

The geometric and operating conditions are summarised below:

\section{Regenerator:}

Material: Gd;

Dimension: $30 \mathrm{~mm} \times 21 \mathrm{~mm} \times 90 \mathrm{~mm}, d_{\mathrm{ch}}=0.7-2.0 \mathrm{~mm}$;

Thermophysical properties: $\lambda_{\mathrm{s}}=10.6 \mathrm{~W} / \mathrm{m} \mathrm{K}, c_{\mathrm{s}}=290 \mathrm{~J} / \mathrm{kg} \mathrm{K}, \rho_{\mathrm{s}}=7900 \mathrm{~kg} / \mathrm{m}^{3}$;

Working fluid:

Water

Thermophysical properties: $\lambda_{\mathrm{f}}=0.65 \mathrm{~W} / \mathrm{m} \mathrm{K}, c_{\mathrm{f}}=4180 \mathrm{~J} / \mathrm{kg} \mathrm{K}, \rho_{\mathrm{f}}=1000.0 \mathrm{~kg} / \mathrm{m}^{3}$. Magnets: 
Material: $\mathrm{NdFeB}$;

Dimensions: $100 \mathrm{~mm} \times 50 \mathrm{~mm} \times 25 \mathrm{~mm}$;

Magnetic field intensity: $B_{\min }=0 \mathrm{~T}, B_{\max }=0.8 \mathrm{~T}$.

CHEX:

Dimensions: $d_{\mathrm{i}, \mathrm{c}}=4.0 \mathrm{~mm}, d_{\mathrm{o}, \mathrm{c}}=6.0 \mathrm{~mm}, l_{\mathrm{c}}=250.0 \mathrm{~mm}$;

Flow rate: $m_{\mathrm{c}}=250 \mathrm{~g} / \mathrm{s}$.

HHEX:

Dimensions: $d_{\mathrm{i}, \mathrm{h}}=4.0 \mathrm{~mm}, d_{\mathrm{o}, \mathrm{h}}=6.0 \mathrm{~mm}, l_{\mathrm{h}}=250.0 \mathrm{~mm}$;

Flow rate: $m_{\mathrm{h}}=250-500 \mathrm{~g} / \mathrm{s}$.

Displacer:

Dimensions: $R=5-50 \mathrm{~mm}, d_{\mathrm{p}}=16 \mathrm{~mm}, l_{\mathrm{d}}=2 R=10-100 \mathrm{~mm}$.

\section{Mathematical model}

The mathematical models are described below for the conductive heat transfer in solid MCM and convective heat transfer in channels of the regenerator, MCE, heat transfer in the cold and hot end heat exchangers and displacer.

\subsection{Conjugated heat transfer in regenerator}

Figure 2 shows a schematic of the microchannel regenerator which has the width $W$, height $H$ and length $L$. A number of circular channels of diameter $d_{\mathrm{ch}}$ are made. The regenerator is placed in a housing and the flow distribution in channels is assumed to be uniform. Considering symmetry, conjugated conductive heat transfer in the MCM wall and convective heat transfer in one channel are simulated. The $x$-coordinate is taken at the center of the channel from the cold end.

The conservations of mass, momentum and energy are written as:

$$
\begin{aligned}
& \nabla \cdot \boldsymbol{u}=0 \\
& \rho_{\mathrm{f}}\left(\frac{\partial \boldsymbol{u}}{\partial t}+\boldsymbol{u} \cdot \nabla \boldsymbol{u}\right)=-\nabla P+\mu_{\mathrm{f}}\left(\nabla^{2} \boldsymbol{u}\right) \\
& \frac{\partial T_{\mathrm{f}}}{\partial t}+\boldsymbol{u} \cdot \nabla T_{\mathrm{f}}=\alpha_{\mathrm{f}}\left(\nabla^{2} T_{\mathrm{f}}\right) \\
& \frac{\partial T_{\mathrm{s}}}{\partial t}=\alpha_{\mathrm{s}}\left(\nabla^{2} T_{\mathrm{s}}\right)
\end{aligned}
$$


where $\boldsymbol{u}$ is the velocity of water, $t$ is time, $T_{\mathrm{f}}$ and $T_{\mathrm{s}}$ are temperatures of water and MCM solid, respectively, $\rho_{\mathrm{f}}, \mu_{\mathrm{f}}$ and $\alpha_{\mathrm{f}}$ are the density, dynamic viscosity and diffusivity of water, respectively, and $\alpha_{\mathrm{s}}$ is the diffusivity of the MCM solid.

The boundary conditions are:

$$
\begin{array}{lll}
q=0, u=v=w=0 & \text { at } & x=0, x=L \quad \text { and } y^{2}+z^{2}-d^{2} / 4>0 \\
\lambda_{\mathrm{f}}\left(\frac{\partial T_{\mathrm{f}}}{d \mathbf{n}}\right)=\lambda_{\mathrm{s}}\left(\frac{\partial T_{\mathrm{s}}}{d \mathbf{n}}\right) & \text { at } & 0 \leq x \leq L, y^{2}+z^{2}-d^{2} / 4=0 \\
\frac{\partial T_{\mathrm{s}}}{d \mathbf{n}}=0 & \text { at } & 0 \leq x \leq L, y= \pm \delta / 2,-\delta / 2<z<\delta / 2 \\
\frac{\partial T_{\mathrm{s}}}{d \mathbf{n}}=0 & \text { at } & 0 \leq x \leq L,-\delta / 2<y<\delta / 2, z= \pm \delta / 2
\end{array}
$$

Cold blow (for $t=t_{3}-t_{4}$, see Fig. 6)

$$
\begin{array}{lll}
u_{\mathrm{r}, \mathrm{c}}=\frac{m_{\mathrm{r}}}{\rho_{\mathrm{f}} A_{\mathrm{ch}} n_{\mathrm{ch}}}, T_{\mathrm{r}, \mathrm{c}}=T_{\mathrm{r}, \mathrm{c}, \text { in }} & \text { at } & x=0, y^{2}+z^{2}-d^{2} / 4<0 \\
\frac{\partial \boldsymbol{u}}{\partial \mathbf{n}}=0, \frac{\partial T_{\mathrm{f}}}{\partial \mathbf{n}}=0 & \text { at } & x=L, y^{2}+z^{2}-d^{2} / 4<0
\end{array}
$$

Hot blow (for $t=t_{6}-t_{7}$, see Fig. 6)

$$
\begin{array}{lll}
u_{\mathrm{r}, \mathrm{h}}=\frac{m_{\mathrm{r}}}{\rho_{\mathrm{f}} A_{\mathrm{ch}} n_{\mathrm{ch}}}, T_{\mathrm{r}, \mathrm{h}}=T_{\mathrm{r}, \mathrm{h}, \mathrm{in}} & \text { at } & x=L, y^{2}+z^{2}-d^{2} / 4<0 \\
\frac{\partial \boldsymbol{u}}{\partial \mathbf{n}}=0, \frac{\partial T_{\mathrm{f}}}{\partial \mathbf{n}}=0 & \text { at } & x=0, y^{2}+z^{2}-d^{2} / 4<0
\end{array}
$$

\subsection{Magnetic field source}

Gadolinium is chosen as the MCM. The MCE is implemented using the discrete method [61]. During the processes of magnetization and demagnetization, local temperature at the time $t^{\mathrm{n}+1}($ $t^{\mathrm{n}+1}=t^{\mathrm{n}}+\Delta t$ ) takes a value at the time $t^{\mathrm{n}}$ with an instantaneous temperature jump calculated by Eq. (13).

$$
T_{\mathrm{s}}\left(x, y, z, t^{\mathrm{n}+1}\right)=T_{\mathrm{s}}\left(x, y, z, t^{\mathrm{n}}\right) \pm \Delta T_{\mathrm{ad}}\left[T_{\mathrm{s}}\left(x, y, z, t^{\mathrm{n}}\right), \Delta B\right]
$$


where $T_{\mathrm{s}}\left(x, y, z, t^{\mathrm{n}+1}\right)$ and $T_{\mathrm{s}}\left(x, y, z, t^{\mathrm{n}}\right)$ represent temperatures in solid MCM at location $(x, y, z)$ and times $t^{\mathrm{n}+1}$ and $t^{\mathrm{n}}$, respectively, $\Delta T_{\mathrm{ad}}$ is positive during magnetization and negative during demagnetization. The adiabatic temperature change is determined by Eq. (14) [65].

$$
\Delta T_{\mathrm{ad}}\left(B, T_{\mathrm{s}}\right)=-\int_{B_{\min }}^{B_{\max }} \frac{T_{\mathrm{s}}}{c_{\mathrm{P}, \mathrm{s}}\left(B, T_{\mathrm{s}}\right)} \frac{\partial m}{\partial T} d B
$$

where $c_{\mathrm{P}, \mathrm{S}}(B, T)$ is the heat capacity of the $\mathrm{MCM}$, and is the sum of the lattice $c_{\text {lat }}(T)$, electronic $c_{\text {ele }}(T)$ and magnetic $c_{\text {mag }}(B, T)$ heat capacities as given below:

$$
\begin{aligned}
& c_{\mathrm{P}, \mathrm{s}}\left(B, T_{\mathrm{s}}\right)=c_{\text {lat }}\left(T_{\mathrm{s}}\right)+c_{\text {ele }}\left(T_{\mathrm{s}}\right)+c_{\text {mag }}\left(B, T_{\mathrm{s}}\right) \\
& c_{\text {lat }}=\frac{9 N_{\mathrm{A}} k_{\mathrm{B}}}{M}\left(\frac{T_{\mathrm{s}}}{T_{\mathrm{De}}}\right)^{3} \int_{0}^{T_{D e} / T_{\mathrm{s}}} \frac{x^{4} e^{x}}{\left(e^{x}-1\right)^{2}} \mathrm{~d} x \\
& c_{\text {ele }}=\gamma_{\mathrm{e}} T_{\mathrm{s}} \\
& c_{\text {mag }}=-B \frac{\partial m}{\partial T}-\frac{1}{2}\left(\frac{3 k_{B} T_{\mathrm{Cu}}}{N_{\mathrm{S}} g^{2} \mu_{\mathrm{B}}^{2} J(J+1)}\right) \frac{\partial\left(m^{2}\right)}{\partial T}
\end{aligned}
$$

where $m$ is the magnetization of the MCM and is determined using the mean field model [65].

$$
\begin{aligned}
& m\left(B, T_{\mathrm{s}}\right)=N g \mu_{\mathrm{B}} J B_{\mathrm{J}}(X) \\
& B_{\mathrm{J}}(X)=\frac{2 J+1}{2 J} \operatorname{coth}\left(\frac{2 J+1}{2 J} X\right)-\frac{1}{2 J} \operatorname{coth}\left(\frac{1}{2 J} X\right) \\
& X\left(B_{\mathrm{J}}, B, T_{\mathrm{s}}\right)=\frac{J g \mu_{\mathrm{B}}}{K_{\mathrm{B}} T_{\mathrm{s}}} B+\frac{3 J T_{\mathrm{Cu}}}{J+1} \frac{B_{\mathrm{J}}(X)}{T_{\mathrm{s}}}
\end{aligned}
$$

where $K_{B}=1.381 \times 10^{-23} \mathrm{~J} / \mathrm{K}$ is the Boltzmann Constant, $\mu_{B}=9.274 \times 10^{-24} \mathrm{~J} / \mathrm{T}$ is the Bohr magneton, $N_{A}=6.022 \times 10^{23} \mathrm{~mol}^{-1}$ is the Avogadro's number, $G=2$ is the Lande factor, $J=3.5 \mathrm{~h}$ is the angular momentum, $N_{\mathrm{s}}=3.83 \times 10^{28} \mathrm{~kg}^{-1}$ is the number of magnetic spins, $T_{\mathrm{Cu}}=294.0 \mathrm{~K}$ is the Curie temperature of $\mathrm{Gd}, T_{\mathrm{De}}=173 \mathrm{~K}$ is the Debye temperature.

The calculation of the MCE using the mean field model involves iteration and for a 3D conjugated conduction and convection in the microchannel regenerator it is time consuming. To 
speed up computation of the dynamic simulation of the heat pump/refrigerator system in the present work, polynomial fit was applied to correlate $\Delta T_{\mathrm{ad}}$ and $T_{\mathrm{s}}$. For a given magnetic field intensity, $\Delta T_{\mathrm{ad}}$ is solely a function of local temperature $T_{\mathrm{s}}$ of the solid. Two polynomials (Eqs. (22) and (23)) were found for temperature lower and higher the Curie temperature $\left(T_{\mathrm{Cu}}=294.0 \mathrm{~K}\right)$. Figure 4 plots $\Delta T_{\mathrm{ad}}$ as a function of temperature for $\mathrm{Gd}$ for the variation of the magnetic field intensity of $0.8 \mathrm{~T}$.

$$
\begin{array}{ll}
\Delta T_{\mathrm{ad}}\left(T_{\mathrm{s}}, \Delta B=0.8 \mathrm{~T}\right)=a_{3} T_{\mathrm{s}}^{3}+a_{2} T_{\mathrm{s}}^{2}+a_{1} T_{\mathrm{s}}+a_{0} & \text { for } T_{\mathrm{s}} \leq T_{\mathrm{Cu}} \\
\Delta T_{\mathrm{ad}}\left(T_{\mathrm{s}}, \Delta B=0.8 \mathrm{~T}\right)=b_{3} T_{\mathrm{s}}^{3}+b_{2} T_{\mathrm{s}}^{2}+b_{1} T_{\mathrm{s}}+b_{0} \quad \text { for } T_{\mathrm{s}}>T_{\mathrm{Cu}}
\end{array}
$$

where $a_{3}=6.607467 \times 10^{-5}, a_{2}=5.301642 \times 10^{-2}, a_{1}=14.214112, a_{0}=-1.271077 \times 10^{3}, b_{3}=$ $1.048491 \times 10^{-4}, b_{2}=1.013157 \times 10^{-1}, b_{1}=32.642460, b_{0}=3.506776 \times 10^{3}$. Two polynomials are also plotted in Fig. 4. Good agreements are seen between the predictions by the mean field model and two polynomials. Equations (22) and (23) are used in the present simulation.

\subsection{Cold and hot end heat exchangers}

Following Engelbrecht [38], the $\varepsilon-N T U$ method is used to simulate heat transfer in the HHEX and CHEX. The flow arrangement in the heat exchangers is set to be counter-current when fluid enters the heat exchanger from the regenerator side and becomes parallel when the flow direction is reversed. The heat transfer rates at the HHEX and CHEX, the heating and cooling loads, can be calculated by Eq. (24).

$$
Q_{\mathrm{j}}=\frac{1}{\tau} \int_{0}^{\tau} m_{\mathrm{j}} c_{P, \mathrm{j}}\left(T_{\mathrm{j}, \text { out }}-T_{\mathrm{j}, \text { in }}\right) \mathrm{d} t
$$

where $m_{\mathrm{j}}$ is the mass flow rate, $T_{\mathrm{j}, \text { out }}$ and $T_{\mathrm{j}, \text { in }}$ are the temperatures at the outlet and inlet, respectively, $c_{P, \mathrm{j}}$ is the specific heat capacity of the fluid, $\tau$ is the period of a cycle. Here subscript $\mathrm{j}$ refers to hot or cold i.e. h or c. The temperature at the outlet $T_{\mathrm{j}, \text { out }}$ is calculated by Eq. (25).

$$
T_{\mathrm{j}, \text { out }}=T_{\mathrm{j}, \mathrm{in}}-\varepsilon_{\mathrm{j}} Q_{\mathrm{max}, \mathrm{j}} /\left(m c_{P}\right)_{\mathrm{j}}
$$

where $\varepsilon_{\mathrm{j}}$ is the effectiveness given by Eq. (26)

$$
\varepsilon_{\mathrm{j}}=\frac{1-\exp \left[-N T U_{\mathrm{j}}\left(1-C_{\mathrm{j}}\right)\right]}{1-c_{\mathrm{j}} \exp \left[-N T U_{\mathrm{j}}\left(1-C_{\mathrm{j}}\right)\right]}
$$


$Q_{\text {max }, \mathrm{j}}=\left(m c_{P}\right)_{\min }\left(T_{\mathrm{r}, \mathrm{in}}-T_{\mathrm{j}, \mathrm{in}}\right)$ is the maximum possible heat transfer rate, $C_{\mathrm{j}}=\left(m c_{P}\right)_{\mathrm{j}, \min } /\left(m c_{P}\right)_{\mathrm{j}, \max }$ is the capacity ratio and $\left(m c_{P}\right)_{\mathrm{j}, \text { min }}$ is the minimum heat capacity of the two fluids, $N T U_{\mathrm{j}}=U_{\mathrm{j}} A_{\mathrm{j}, \mathrm{i}}$ $/\left(m c_{P}\right)_{\mathrm{j}, \min }, U_{\mathrm{j}}$ is the overall heat-transfer coefficient, $A_{\mathrm{j}, \mathrm{i}}$ is the heat transfer area, i.e. inside surface area of the inner tube of the CHEX/HHEX.

The overall heat-transfer coefficient $U_{\mathrm{j}}$ is calculated by

$$
U_{\mathrm{j}}=\left[\frac{1}{\alpha_{\mathrm{r}}}+\frac{d_{\mathrm{j}, \mathrm{i}}}{2 \lambda_{w, \mathrm{j}}} \ln \left(\frac{d_{\mathrm{o}, \mathrm{j}}}{d_{\mathrm{i}, \mathrm{j}}}\right)+\frac{d_{\mathrm{j}, \mathrm{i}}}{\alpha_{\mathrm{j}} d_{\mathrm{o}, \mathrm{j}}}\right]^{-1}
$$

where $\alpha_{\mathrm{r}}$ and $\alpha_{\mathrm{j}}$ are the heat-transfer coefficients of the working fluid in the inner tube and the cooling/heating fluid in the annuli of the CHEX/HHEX, respectively. $d_{\mathrm{j}, \mathrm{i}}$ and $d_{\mathrm{j}, \mathrm{o}}$ are the inside and outside diameters of the inner tube of the CHEX/HHEX, respectively. $\lambda_{\mathrm{w}, \mathrm{j}}$ is the thermal conductivity of the inner tube. The heat-transfer coefficients for the fluids in both sides of the HHEX and CHEX are calculated by [66].

$$
\alpha_{\mathrm{j}}=N u \frac{\lambda_{\mathrm{f}, \mathrm{j}}}{d_{\mathrm{h}, \mathrm{j}}}
$$

where $\lambda_{\mathrm{f}, \mathrm{j}}$ is the thermal conductivity of the working fluids in both sides of the HHEX and CHEX, $d_{\mathrm{h}}$ is the hydraulic diameter. $N u$ is the Nusselt number and is calculated by Eqs. (29) and (31).

For $\operatorname{Re}<2300$, Gnielinski [67] correlation is used,

$$
N u=\frac{(f / 8)(\operatorname{Re}-1000) P r}{1+12.7 \sqrt{f / 8}\left(\operatorname{Pr}^{2 / 3}-1\right)}
$$

where $f$ is the Darcy friction factor calculated by the Filonenko [68] correlation

$$
f=(1.58 \ln R e-3.28)^{-2}
$$

Equation (29) is valid in the ranges of $\operatorname{Re}=2300 \sim 10^{6}, \operatorname{Pr}=0.6 \sim 10^{5}$.

For laminar flow $(R e<2300)$,

$$
\begin{gathered}
N u=3.66 \\
f=16 / R e
\end{gathered}
$$

\subsection{Displacer}


Due to the horizontal reciprocating motion of the piston, the mass flow rate of the working fluid is determined by

$$
m_{\mathrm{r}}=\frac{1}{2} \pi \rho_{\mathrm{f}} d_{\mathrm{p}}^{2} R f \sin (2 \pi f t)
$$

where $R$ is the radius of the crank disk of the displacer, $f$ is the rotational frequency of the crank disk and $d_{\mathrm{p}}$ is the cross-sectional diameter of the cylinder.

The average mass flow rate during the cold or hot blows is determined as

$$
m_{\mathrm{r}, \mathrm{av}}=\frac{1}{\tau_{\text {flow }}} \int_{0}^{\tau_{\text {flow }}} m_{\mathrm{r}}(t) \mathrm{d} t
$$

With the piston position $x=0$ shown in Fig. 5, there is a maximum volume of fluid inside the cold end piston chamber and a minimum volume inside the hot end piston chamber. As piston starts moving along $x$ direction the fluid volume inside the hot end chamber commences to increase and by piston completing its full stroke $l$ cold end piston chamber gets fully evacuated and the hot end chamber contains the maximum volume of the fluid.

Assuming instant mixing of the fluid inside the chamber, the enthalpy-averaged bulk temperature $T_{\mathrm{b}, \mathrm{j}}$ of the fluid inside the chamber is calculated by

$$
T_{\mathrm{b}, \mathrm{j}}=\frac{\int_{0}^{\tau_{\text {flow }}} m_{\mathrm{r}}(t) T_{\mathrm{r}, \mathrm{j}, \text { out }} \mathrm{d} t}{\int_{0}^{\tau_{\text {flow }}} m_{\mathrm{r}}(t) \mathrm{d} t}
$$

The transient accumulation (+) or evacuation (-) of the fluid inside the hot and cold end chambers during the cold and hot blows $m_{\mathrm{r} \text {, tot }}$ is calculated by

$$
m_{\mathrm{r}, \text { tot }}=m_{\mathrm{r}, \text { init }} \pm \int_{0}^{\tau_{\mathrm{flow}}} m_{\mathrm{r}}(t) \mathrm{d} t
$$

where $m_{\mathrm{r} \text {, init }}$ is the initial mass of the fluid inside the chamber.

\subsection{Power consumption}

The average pumping power required to circulate the working fluid in the system is given as

$$
W_{\mathrm{p}}=\frac{1}{2 \tau} \int_{0}^{\tau} \Delta P d_{\mathrm{p}}^{2} R f \sin (2 \pi f t) \mathrm{d} t
$$

where $\Delta P$ is the pressure drop of the fluid inside the system 


$$
\Delta P=\sum_{i=1}^{N} \Delta P_{i}
$$

where $\Delta P_{i}$ is the pressure drop in the $i$ th component/loop of the system and can be calculated as

$$
\Delta P_{i}=f \frac{4 L}{d_{h}} \frac{\rho_{\mathrm{f}} u^{2}}{2}
$$

where $f$ is the Darcy friction factor and is calculated using Eqs. (30) and (32), $u$ is the velocity of the fluid in the section and $L$ and $d_{\mathrm{h}}$ are, respectively, the length and the hydraulic diameter of the $i$ th component of the system.

\subsection{Operating procedure}

As indicated in Fig. 1, the magnet travels between two positions (dashed line rectangles) where the intensity of the magnetic field in the regenerator varies from $B_{\max }$ to $B_{\min }$ periodically. The crank disk rotates at a uniform angular velocity $\omega$ and correspondingly the piston reciprocates horizontally in the cylinder. The working fluid therefore flows forwards and backwards across the CHEX, regenerator and HHEX. As shown in Fig. 6, the mass flow rate of the working fluid is a sinusoidal function of time during cold and hot blow periods and is zero during the magnetization and demagnetization periods.

The operation process of a cycle can be divided into the following four steps:

1) Magnetization: the magnet moves towards the regenerator between the time $t_{1}$ and $t_{3}$, the intensity of the magnet field increases from $B_{\min }$ to $B_{\max }$. The MCE is implemented at time $t_{2}$ (mid of the no-flow period) using Eq. (13). The temperature of each control volume of the regenerator solid $T_{\mathrm{s}}$ is retrieved, control volumes with $T_{\mathrm{s}} \leq T_{\mathrm{Cu}}$ are updated using Eq. (22) while for control volumes with $T_{\mathrm{s}}>T_{\mathrm{Cu}}$ Eq. (23) is used. The magnetization/demagnetization stages are taking place instantaneously and the no-flow periods are taken to be zero;

2) Cold blow: Between the time $t_{3}$ and $t_{4}$, the regenerator remains in the magnet field $\left(B_{\max }\right)$, the working fluid flows forwards (cold blow) through the microchannels and the MCM solid is cooled down;

3) Demagnetization: the magnet moves backwards away from the regenerator between the time $t_{4}$ and $t_{6}$, the intensity of the magnet field decreases from $B_{\max }$ to $B_{\min }$. The MCE is implemented at time $t_{5}$ (mid of the second no-flow period) and consequently the local temperatures in the MCM solid decrease to the values determined by Eq. (13), (22) and (23); 
4) Hot blow: Between the time $t_{6}$ and $t_{7}$, the regenerator remains outside the magnet field $\left(B_{\min }\right)$, the working fluid flows backwards (in the reverse direction of cold blow) through the microchannels and the MCM solid is heated up.

The cycle of magnetization, cooling down, demagnetization and heating up then repeats. The period of a cycle $\tau$ is $t_{7}-t_{1}$. The operation process above is illustrated in Fig. 6. It is noted that the interaction between the magnet and regenerator takes place between $t_{1}$ and $t_{3}$ and $t_{4}$ and $t_{6}$ where the mass flow rate of the working fluid $m_{\mathrm{r}}$ approaches zero and hence the convective heat transfer is the lowest whereas between $t_{3}$ and $t_{4}$ and $t_{6}$ and $t_{7}$ the mass flow rate is higher and hence the convective heat transfer is higher.

The pumps of the cooling and heating loops work continuously and the heat exchange takes place when the working fluid passes through the inner tubes of the CHEX and HHEX. The cooling and heating loads are evaluated by measuring the mass flow rate and temperature rise in the cooling and heating loops, respectively.

\subsection{Computation scheme}

Figure 7 shows the flow chart of the solution procedure. The procedure starts by creating 3D geometry and grid for the microchannel regenerator (Fig. 2(b)) and defining the operating parameters such as the magnetic field intensity, the cycle frequency (hot and cold blow durations, magnetisation and demagnetisation durations) and the mass flow rate. The initial temperature (at $t=$ $0 \mathrm{~s}$ ) of the regenerator solid and the fluid inside the entire system is taken to be $293.0 \mathrm{~K}$. The mass flow rate and magnetic field profiles are shown in Fig. 6.

Equations (1) to (4) together with the corresponding boundary conditions (Eqs. (5) - (12)) were numerically solved using FLUENT. The SIMPLE algorithm was chosen. The simulations of the regenerator, CHEX, HHEX and displacer as well as the magnet were all coupled together considering the working fluid flow and interactive control of the displacer and magnet step motor. This was implemented using the user defined function (UDF). The flowchart of the simulation procedure is shown in Fig. 7.

The computational domain for the conjugated heat transfer is shown in Fig. 8. The fluid (channel for water flow) and solid (MCM) zones are shown by green and black colours, respectively. The domain was discretised into hexagonal cells. To study the grid indepence, steadystate flow and heat transfer of water as specified in Table 3 was computed (single blow, flow from one direction only) using various grid spacings $n_{\Delta x}, n_{\Delta y}$ and $n_{\Delta z}$ along $x, y$ and $z$ directions, respectively. As can be seen from Table 3, the average Nu converges as the number of the mesh increases. A grid size of $10 \times 10 \times 90$ was therefore selected for the present set of simulations. 


\section{Results and discussion}

\subsection{Model validation}

To validate the models and the solution procedure, the results of the recent simulation were compared with the experimental data of Dupuis et al. [69] in Table 3. The simulation model of 2D parallel plate regenerator of Dupuis et al. [69] is shown in Fig. 9. In Fig. 10, the predicted cold and hot end temperatures are in general agreement with the experimental data of Dupuis et al. [69]. The temperature span predicted in the present work is higher than the corresponding experimental values. The difference of the experimental and numerical results may be attributed to the simplifications and approximations of the present work as described in section 3.

\subsection{Parametric study on microchannel regenerator}

Parametric study has been conducted to investigate the performance of the refrigerator with microchannel regenerator. The transient temperatures at the two ends of the microchannel regenerator are shown in Fig. 11(a). With increase of time, the transient temperature at the hot end $\left(T_{\mathrm{h}}\right)$ increases and the transient temperature at the cold end $\left(T_{\mathrm{c}}\right)$ decreases. After 200 seconds, the transient temperatures at the two ends are stable. A maximum temperature span $\left(T_{\mathrm{h}}-T_{\mathrm{c}}\right)$ of $\sim 23 \mathrm{~K}$ was achieved across the two ends of the regenerator for cycle frequency of $2.0 \mathrm{~Hz}$. Figure 11(b) shows variation of no-load temperature span with the utilization $(\varphi)$. The temperature span firstly increases and then decreases with increase of the utilization $(\varphi)$ with a peak value of $\sim 20 \mathrm{~K}$ at $\varphi=$ 0.1 .

\subsubsection{Effect of utilization}

Mass flow rate has a significant influence on the regenerator performance. This is represented by a dimensionless parameter 'utilization' $\varphi$ defined as

$$
\varphi=\frac{m_{\mathrm{r}, \mathrm{av}} c_{\mathrm{f}} \tau_{\mathrm{f}}}{m_{\mathrm{s}} c_{\mathrm{s}}}
$$

where $\tau_{\mathrm{f}}$ is the flow time, $m_{\mathrm{s}}$ and $c_{\mathrm{s}}$ are the mass and heat capacity of the MCM. Figure 12 shows the effect of utilization on the cooling capacity. For the given regenerator size, utilization is changed by varying mass flow rate of the working fluid. Mass flow rate is controlled by changing the crank-disk radius $R$ as is seen in Fig. 5. Different values of the utilization, mass flow rate and crank disk radius $R$ are listed in Table 5. The influence of utilization on cooling capacity has also been investigated for different porosity and frequency, as shown in Figs. 12(a) and 12(b). The cooling capacity is found to have a peak value in the utilization range of $0.1-0.2$. It also has a negative trend for the utilization values higher than 0.2 and a positive trend for utilization less than 
$0.1(0.2<\varphi<0.1)$. At very low utilization $(\varphi<0.1)$, the relative smaller mass flow rate corresponds to a reduced convective heat transfer rate and hence lower cooling capacity. Higher utilization values $\varphi>0.3$ (larger mass flow rate) hinder the development of temperature gradient across two ends of the regenerator due to increased convective heat transfer rate and hence reduces the cooling capacity.

\subsubsection{Effect of porosity}

The porosity of the regenerator $\varepsilon$ is defined as:

$$
\varepsilon=\frac{n_{\mathrm{ch}} V_{\mathrm{ch}}}{V_{\mathrm{t}}}=\frac{\pi n_{\mathrm{ch}} d_{\mathrm{ch}}^{2}}{4 W H}
$$

where $n_{\mathrm{ch}}$ is the number of channels, $V_{\mathrm{ch}}$ is the volume of fluid inside one microchannel and $V_{\mathrm{r}}$ is the total volume of regenerator. Numerical simulations were carried out for different values of porosity $\varepsilon$. The porosity varied by taking different values of the channel diameter to inter-channel spacing ratio $d_{\mathrm{ch}} / \delta$. The range of $d_{\mathrm{ch}} / \delta$ lies between 0 and 1; and is varied by changing the channel spacing $\delta$ for a given $d_{\mathrm{ch}}$. Varying $\delta$, would limit the maximum number of channels $n_{\mathrm{ch}}$ and hence the available heat transfer area for the given regenerator size which in this case is $30 \times 21 \times 90 \mathrm{~mm}^{3}$. For instance, for $d_{\mathrm{ch}}=2.0 \mathrm{~mm}$ and $\delta=2.5 \mathrm{~mm}$, the maximum number of channels are 88 and the corresponding regenerator porosity comes out to be 0.25 . Table 7 lists different cases of porosity used in the numerical simulation to obtain cooling capacity curves in Fig. 13.

Figure 13 shows the effect of regenerator porosity on the cooling capacity of the AMR system. The cooling capacity increases as the porosity is increased till it reaches its maximum at the porosity value of $\sim 0.5$. For smaller porosity (larger volume of $\mathrm{MCM}$ ), more heat is dispersed (conducted) within the MCM as compared to the heat transfer by fluid resulting in lower cooling capacity and opposite is the case for larger porosity (smaller volume of MCM) where convective heat transfer rate is higher than heat conduction rate within the MCM insufficient enough to develop temperature gradient. Channel diameter is found to have a weak influence on the cooling capacity nevertheless smaller channel diameter gives slightly better performance for the given porosity as can be noticed for the case of $d_{\mathrm{ch}}=1.0 \mathrm{~mm}$ due to larger available heat transfer area for given regenerator porosity.

\subsubsection{Effect of cycle frequency}

The cycle frequency is defined as the number of operating cycles completed in a second. As shown in Fig. 6, the total time taken for a cycle is the sum of the times taken for the four stages. 


$$
\tau=\tau_{1}+\tau_{2}+\tau_{3}+\tau_{4}
$$

where $\tau_{1}$ and $\tau_{3}$ are the periods of magnetization and demagnetization while $\tau_{2}$ and $\tau_{4}$ are the periods of cold and hot blows, respectively. The MCE for the magnetization and demagnetization processes was implemented using the discrete method so the time periods $\tau_{1}$ and $\tau_{3}$ are zero. Hence the cycle time period is the sum of the cold and hot blow periods.

Figure 14 shows the effect of cycle frequency on cooling capacity for a utilization value of 0.2 for different regenerator porosities. Cooling capacity linearly increases with increasing in cycle frequency. This is due to the fact the more MCEs and convective heat transfer occur in unit time. Similar results were reported by Nielsen et al. [53] and Oliviera et al. [58].

Very high operating frequencies are not possible in typical magnetocaloric systems where mechanical systems are employed to pump the fluid in the system and to operate the magnetic field source. Also higher frequency operation would require higher power consumption for the fluid displacer/pump and the magnetic field slider resulting in a lower overall COP of the system. Permanent magnet based magnetic field sources have been shown to operate up to $10 \mathrm{~Hz}$ [12] but still there are limits on the fluid circulation in the system. Innovative approaches such as usage of thermoelectric switches have been proposed by Kitanovski and Egolf [33]. Thermal switches are capable of operating at frequencies of the order of 100 [70].

\subsubsection{Effect of magnetic field intensity}

Permanent magnet assembly can produce a maximum magnetic field of up to 1.6 T. Effect of magnetic field intensity on the cooling power of the system has been investigated under various magnetic field intensities. Figure 15 shows the variation of $\Delta T_{\text {ad }}$ with different magnetic field intensity changes calculated using mean field model. As shown in Fig. 16(a) and 16(b) as the magnetic field intensity increases the no-load temperature span and cooling capacity increase for given operating conditions. A positive linear trend can be seen between the change in magnetic field intensity and the cooling capacity. For higher change in magnetic field intensity, the corresponding temperature rise and drop of the MCM are higher, leading to a larger temperature span across two ends of the regenerator and hence higher cooling capacity. As can be seen in Fig. 16(b) the gradient of cooling capacity curve is higher for higher cycle frequency, implying that for a given increment in $\Delta \mathrm{B}$ the change in cooling capacity will be larger for the system operating at higher frequency.

\subsubsection{Effect of temperature span}


Imposed temperature span is another parameter used to characterise the magnetocaloric system. Temperature of the hot end heat exchanger is usually fixed at room temperature while that of cold end heat exchanger is varied to obtain a set of $\Delta T_{\mathrm{s}}$ values. The corresponding cooling capacity of the system is thus determined. Figure 17 shows the schematic of two temperature differences in the system. Figure 18 shows the variation of cooling capacity with imposed temperature span for different $\Delta B$ values at $\varphi=0.2$ and $f=2.0 \mathrm{~Hz}$. A negative linear correlation is found between cooling capacity and temperature span. As the temperature span is increased the cooling capacity decreases till it becomes negative. For $\Delta B=0.8$, cooling capacity becomes negative for $\Delta T_{\mathrm{s}}=7.5 \mathrm{~K}$ and $\Delta T_{\mathrm{s}}=$ $13.0 \mathrm{~K}$ for $\Delta B=1.4 \mathrm{~T}$.

\subsubsection{Effect of flow rate profile}

Figure 19(a) shows two different mass flow rate profiles. Profile-I is sinusoidal waveform typically generated in motor operate piston-displacer and profile-II is of constant mass flow rate provided by centrifugal pump. The performance of the system is compared under two profiles for cases A and B (see Table 6).

As can be seen in Fig. 19(b), cooling capacity vs utilization curves are given for two profiles. Cooling capacity curve for case A has a higher peak for constant mass flow rate (profile-I) as compared to the sinusoidal profile. Also, the curve peak is seen to be shifted at $\varphi=0.4$ for profile-II whereas for profile-I it was at $\varphi=0.2$. Case B also has higher cooling capacity curve for all the utilization values for profile-II as compared to profile-I. For the case of sinusoidal profile of mass flow rate, for given utilization the rate of heat transfer at cold end heat exchanger $Q_{\mathrm{c}}$ also varies sinusoidally yielding a lower average cooling capacity per AMR cycle. However, for the case of constant mass flow rate, the average $Q_{\mathrm{c}}$ is higher for the same utilization.

\subsubsection{Comparison of microchannel and parallel-plate regenerators}

The performance of microchannel regenerators is compared with that of parallel-plate regenerators. The physical model of the parallel plate regenerator is shown in Fig. 9. The comparison of the two regenerators is based on the same mass of the MCM and overall dimensions. The details of the regenerators are summarised in Table 6. Cases F and G are for microchannel and cases $\mathrm{H}$ and I are for parallel-plate.

Figure 20(a) shows the variation of the cooling capacity with utilization for the four cases. It is seen that the cooling capacity takes peak values at $\varepsilon=0.1-0.2$ and decreases as utilization further increases. Microchannel channel case F has $28 \%$ higher cooling capacity than microchannel case G. The reason is the higher heat transfer area per unit volume for case F. Microchannel case F shows $7 \%$ higher cooling capacity compared with parallel-plate regenerator case H. Microchannel case G 
shows $10 \%$ higher cooling capacity than its equivalent parallel-plate case I. Figure 20(b) shows the cooling capacity per unit pumping power for two types of the regenerators. The pumping power for the regenerators is calculated using Eqs. (37) - (39). The cooling capacity per unit pumping power takes the highest value for microchannel regenerator case $\mathrm{F}$ at $\varepsilon=0.05$.

\section{Concluding remarks}

A hybrid numerical simulation for the room temperature magnetic refrigerator has been performed using Fluent. The three dimensional model for the microchannel regenerator is solved using finite-volume method and $\varepsilon-N T U$ method is used for two heat exchangers. The numerical results show that the cooling capacity of the magnetic refrigerator is sensitive to the utilization, porosity, cycle frequency and flow rate profile. At a change of the intensity of magnetic field $0.8 \mathrm{~T}$, When, the maximum predicted cooling capacity is about $22 \mathrm{~W}$ at the utilization, porosity and cycle frequency being $0.2,0.5$ and $5.0 \mathrm{~Hz}$, respectively, but the no-load temperature span is about $23 \mathrm{~K}$ at utilization of 0.1 . The cooling capacity increases linearly with the increase of the cycle frequency in the range studied and decreases linearly with the increase of the temperature difference between two reservoirs, and the more the change of magnetic field intensity is, the more the cooling capacity. Microchannel regenerator shows higher cooling capacity than parallel-plate regenerator by a maximum of $\sim 7 \%$.

\section{Acknowledgments}

A PhD studentship by the University of Engineering and Technology Lahore, Pakistan and EU research grant FP7-2010-IRSES-269205 are gratefully acknowledged. The work was also partly financially supported by the National Natural Science Foundation of China (No. 51176050).

\section{Nomenclature}

A heat transfer area

$a_{\mathrm{p}} \quad$ heat transfer area per unit volume

$B \quad$ intensity of magnetic field

$\Delta B \quad$ maximum change in intensity of magnetic field

$C$ ratio of the principal heat capacities

$c_{P} \quad$ specific isobaric heat capacity

d diameter

$d_{\mathrm{i}} \quad$ inside diameter

$d_{\mathrm{h}} \quad$ hydraulic diameter

$d_{\text {o }} \quad$ outside diameter 


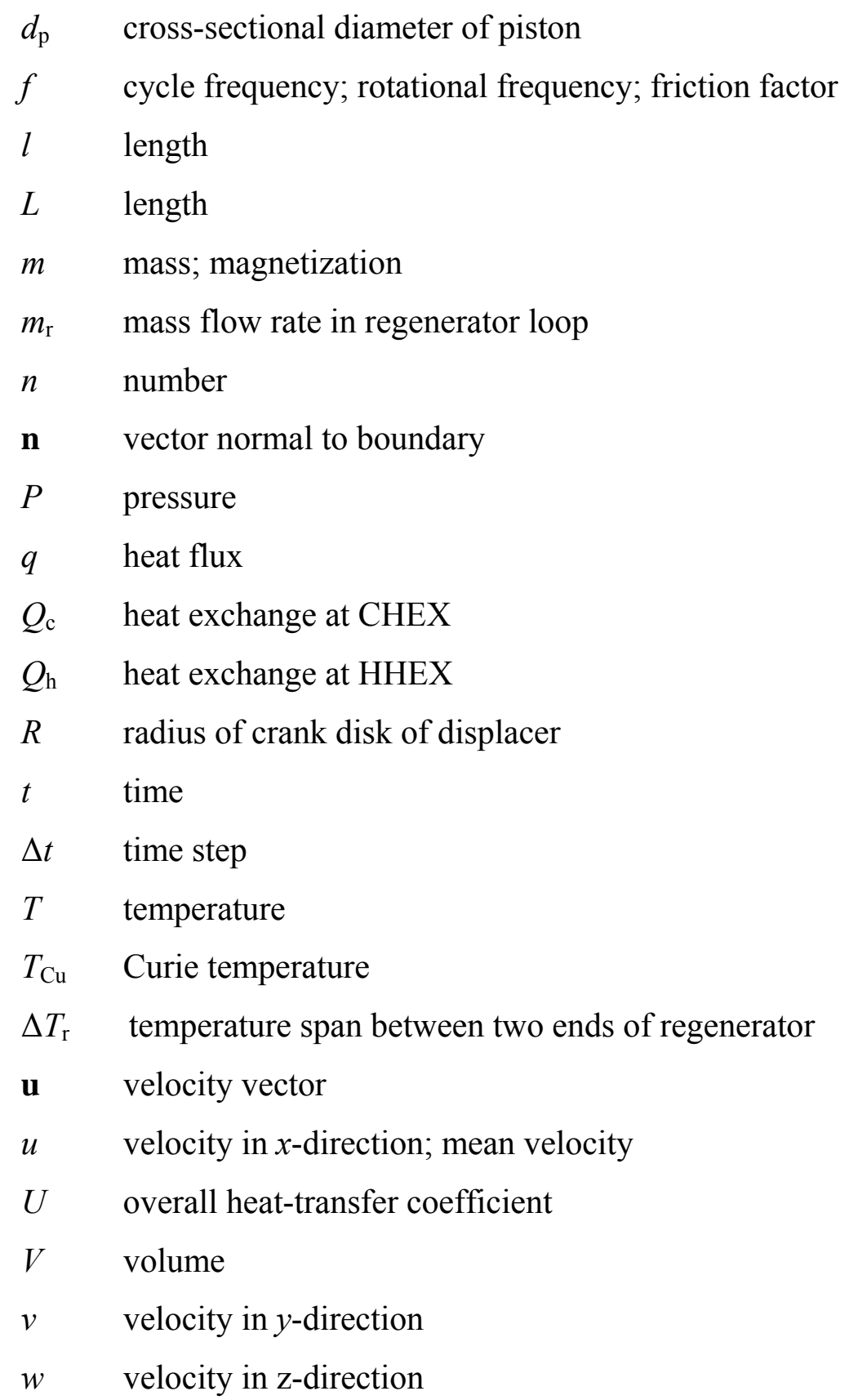

\section{Greek}

$\alpha \quad$ thermal diffusivity

$\delta \quad$ spacing; thickness

$\Delta \quad$ change; difference

$\varepsilon \quad$ porosity; effectiveness; uncertainty $\varepsilon=\left(\Delta T_{\mathrm{r}, \text { num }}-\Delta T_{\mathrm{r} \text {,exp }}\right) / \Delta T_{\mathrm{r} \text {,exp }} \%$

$\lambda$ thermal conductivity

$\mu \quad$ dynamic viscosity

$\rho$ density

$\tau \quad$ period of a cycle

$\omega \quad$ angular velocity of the crank disk 


\begin{tabular}{ll} 
Subscript \\
ad & adiabatic \\
b & bulk \\
c & cold \\
cf & counter-current flow \\
ch & channel \\
ele & electronic \\
exp & experiment \\
f & fluid \\
h & hot, hydraulic \\
i & inside \\
init & initial \\
in & inlet \\
j & r, h or c \\
lat & lattice \\
mag & magnetic \\
max & maximum \\
min & minimum \\
num & numerical \\
o & outside \\
out & outlet \\
pl & plate \\
s & regenerator \\
tot & total \\
w & wall \\
\hline
\end{tabular}

\section{Acronyms}

AMR active magnetocaloric regenerator

CHEX cold and heat exchanger

COP coefficient of performance

HHEX hot end heat exchanger

MCE magnetocaloric effect

MCM magnetocaloric material

NTU number of transferred units 


\section{References}

[1]. Yu, B. F., Liu, M., Egolf, W. and Kitanovski, A., A review of magnetic refrigerator and heat pump prototypes built before the year 2010, International Journal of Refrigeration, 36 (2010): p. 1029-1060.

[2]. Zimm, C., Jastrab, A., Sternberg, A., Pecharsky, V., Gschneidner Jr., K., Osborne, M. and Anderson, I., Description and performance of a near-room temperature magnetic refrigerator, Advances in Cryogenic Engineering, 43 (1998): p. 1759-1766.

[3]. Zimm, C., Boeder, A., Chell, J., Sternberg, A., Fujita, A., Fujieda, S. and Fukamichi, K., Design and performance of a permanent-magnet rotary refrigerator, International Journal of Refrigeration, 29 (2006): p. 1302-1306.

[4]. Jacobs, S., Auringer, J., Boeder, A., Chell, J., Komorowski, L., Leonard, J., Russek, S. and Zimm, C., The performance of a large-scale rotary magnetic refrigerator, International Journal of Refrigeration, 37 (2014): p. 84-91.

[5]. Hirano, N., Nagaya, S., Takahashi, M., Kuriyama, T. and Ito, K., Development of magnetic refrigerator for room temperature application, Advances in Cryogenic Engineering, 47 (2002): p. 1027-1034.

[6]. Okamura, T., Rachi, R., Hirano, N. and Nagaya, S., Improvements of 100W class room temperature. 2007: Portoz, Slovenia.

[7]. Lu, D. W., Xu, X. N., Wu, H. B. and Jin, X., A Permanent magnet magneto-refrigerator study on using $\mathrm{Gd} / \mathrm{Gd}-\mathrm{Si}-\mathrm{Ge} / \mathrm{Gd}-\mathrm{Si}-\mathrm{Ge}-\mathrm{Ga}$ Alloys, , in proc: 1st IIF-IIR International Conference on Magnetic Refrigeration at Room Temperature, Thermag I, 2005, Montreux, Switzerland, 27-30 September.

[8]. Bahl, C. R. H., Petersen, T. F., Pryds, N. and Smith, A., A versatile magnetic refrigeration test device, Review Of Scientific Instruments, 79 (2008).

[9]. Bahl, C. R. H., Engelbrecht, K., Bjørk, R., Eriksen, D., Smith, A., Nielsen, K. K. and Pryds, N., Design concepts for a continuously rotating active magnetic regenerator, International Journal of Refrigeration, 34 (2011): p. 1792-1796.

[10]. Engelbrecht, K., Eriksen, D., Bahl, C. R. H., Bjørk, R., Geyti, J., Lozano, J. A., Nielsen, K. K., Saxild, F., Smith, A. and Pryds, N., Experimental results for a novel rotary active magnetic regenerator, International Journal of Refrigeration 35 (2012): p. 1498-1505.

[11]. Lozano, J. A., Engelbrecht, K., Bahl, C. R. H., Nielsen, K. K., Eriksen, D., Olsen, U. L., Barbosa Jr., J. R., Smith, A., Prata, A. T. and Pryds, N., Performance analysis of rotary magnetic refrigerator, Applied Energy, 111 (2013): p. 669-680.

[12]. Lozano, J. A., Engelbrecht, K., Bahl, C. R. H., Nielsen, K. K., Barbosa Jr, J. R., Prata, A. T. and Pryds, N., Experimental and numerical results of a high frequency rotating active magnetic refrigerator, International Journal of Refrigeration, 37 (2014): p. 92-98.

[13]. Bahl, C. R. H., Engelbrecht, K., Eriksen, D., Lozano, J. A., Bjørk, R., Geyti, J., Nielsen, K. K., Smith, A. and Pryds, N., Development and experimental results from a $1 \mathrm{~kW}$ prototype AMR, International Journal of Refrigeration, 37 (2014): p. 78-83.

[14]. Trevizoli, P. V., Barbosa Jr, J. R. and Ferreira, R. T. S., Experimental evaluation of a Gd based linear reciprocating active magnetic regenerator test apparatus, International Journal of Refrigeration, 34 (2011): p. 1518-1526.

[15]. Rowe, A., Tura, A., Richard, A., Chahine, R. and Barclay, J., An overview of operating experience using the AMR test apparatus, Advances in Cryogenic Engineering, 49 (2004): p. $1721-1728$.

[16]. Rowe, A. and Tura, A., Experimental investigation of a three-material layered active magnetic regenerator, International Journal of refrigeration, 29 (2006): p. 1286-1293. 
[17]. Rowe, A. and Tura, A., Experimental studies of near room temperature magnetic refrigeration, International Journal of Refrigeration, 29 (2006): p. 1286-1293.

[18]. Tura, A., Nielsen, K. K. and Rowe, A., Experimental and modeling results of a parallel plate-based active magnetic regenerator, International Journal of Refrigeration, 35 (2012): p. 1518-1527.

[19]. Arnold, D. S., Tura, A., Ruebsaat-Trott, A. and Rowe, A., Design improvements of a permanent magnet active magnetic refrigerator, International Journal of Refrigeration, 37 (2013): p. 36-42.

[20]. Kitanovski, A., Egolf, P. W. and Poredos, A., Rotary magnetic chillers with permanent magnets, International Journal of Refrigeration, 35 (2012): p. 1055-1066.

[21]. Tusek, J., Kitanovski, A., Prebil, I. and Poredos, A., Dynamic operation of an active magnetic regenerator (AMR): Numerical optimization of a packed-bed AMR, International Journal of Refrigeration, 34 (2011): p. 1507-1517.

[22]. Tusek, J., Kitanovski, A., Zupan, S., Prebil, I. and Poredos, A., A comprehensive experimental analysis of gadolinium active magnetic regenerators, Applied Thermal Engineering, 53 (2013): p. 57-66.

[23]. Tusek, J., Kitanovski, A., Tomc, U., Favero, C. and Poredos, A., Experimental comparison of multi-layered $\mathrm{LaFeCoSi}$ and single-layered $\mathrm{Gd}$ active magnetic regenerators for use in a room temperature magnetic refrigerator, International Journal of Refrigeration, 37 (2014): p. 117-126.

[24]. Aprea, C., Greco, A., Maiorino, A., Mastrullo, R. and Tura, A., Initial experimental results from a rotary permanent magnet magnetic refrigerator, International Journal of Refrigeration, 43 (2014): p. 111-122.

[25]. Tagliafico, L. A., Scarpa, F., Valsuani, F. and Tagliafico, G., Preliminary experimental results from a linear reciprocating magnetic refrigerator prototype, Applied Thermal Engineering, 52 (2013): p. 492-497.

[26]. Gatti, J. M., Muller, C., Vasile, C., Brumpter, G., Haegel, P. and Lorkin, T., Magnetic heat pumps - Configurable hydraulic distribution for a magnetic cooling system, International Journal of Refrigeration, 2013 (2013): p. 1-11.

[27]. Legait, U., Guillou, F., Kedous-Lebouc, A., Hardy, V. and Almanza, M., An experimental comparison of four magnetocaloric regenerators using three different materials, International Journal of Refrigeration, 37 (2014): p. 147-155.

[28]. Park, I., Kim, Y. and Jeong, S., Development of the tandem reciprocating magnetic regenerative refrigerator and numerical simulation for the dead volume effect, International Journal of Refrigeration, 36 (2013): p. 1741-1749.

[29]. Kotani, Y., Kansha, Y., Ishizuka, M. and Tsutsumi, A., Experimental investigation of an active magnetic regenerative heat circulator applied to self-heat recuperation technology, Applied Thermal Engineering, 70 (2014): p. 1202-1207.

[30]. Czernuszewicz, A., Kaleta, J., Królewicz, M., Lewandowski, D., Mech, R. and Wiewiórski, P., A test stand to study the possibility of using magnetocaloric materials for refrigerators, International Journal of Refrigeration, 37 (2014): p. 72-77.

[31]. Gomez, J. R., Garcia, A. D., Catoira, A. D. and Gomez, M. R., Magnetocaloric effect - A review of the thermodynamic cycles in magnetic refrigeration, Renewable and Sustainable Energy Reviews, 17 (2013): p. 74-82.

[32]. Gomez, J. R., Garcia, R. F., Catoira, A. D. and Gomez, M. R., Magnetocaloric effect - A review of the thermodynamic cycles in magnetic refrigeration, Renewable and Sustainable Energy Reviews, 17 (2013): p. 74-82.

[33]. Kitanovski, A. and Egolf, P. W., Innovative ideas for future research on magnetocaloric technologies, International Journal of Refrigeration, 33 (2010): p. 449-464.

[34]. Tura, A. and Rowe, A., Concentric Halbach cylinder magnetic refrigerator cost optimization, International Journal of Refrigeration, 37 (2014): p. 106-116. 
[35]. Siddikov, B. M., Wade, B. A. and Schultz, D. H., Numerical simulation of the active magnetic regenerator, Computers \& Mathematics with Applications, 49 (2005): p. 1525 1538 .

[36]. Dikeos, J., Rowe, A. and Tura, A., Numerical analysis of an active magnetic regenerator (AMR) refrigeration cycle, Advances in Cryogenic Engineering, 51 ( 2006): p. 993-1000.

[37]. Engelbrecht, K. L., Nellis, G. F. and Klein, S. A., A numerical model of an active magnetic regenerator refrigeration system, Cryocoolers, 13 (2005): p. 471-480.

[38]. Engelbrecht, K., A Numerical Model of an Active Magnetic Regenerator Refrigerator with Experimental Validation. 2008, University of Wisconsin, Madison.

[39]. Aprea, C. and Maiorino, A., A flexible numerical model to study an active magnetic refrigerator for near room temperature applications, Applied Energy, 87 (2010): p. 26902698.

[40]. Tagliafico, G., Scarpa, F. and Canepa, F., A dynamic 1-D model for a reciprocating active magnetic regenerator; influence of the main working parameters, International Journal of Refrigeration, 33 (2010): p. 286-293.

[41]. Vuarnoz, A. and Kawanami, T., Numerical analysis of a reciprocating active magnetic regenerator made of gadolinium wires, Applied Thermal Engineering, 37 (2012): p. 388395.

[42]. Plaznik, U., Tusek, J., Kitanovski, A. and Poredos, A., Numerical and experimental analyses of different magnetic thermodynamic cycles with an AMR, Applied Thermal Engineering, 59 (2013): p. 52-59.

[43]. Silva, D. J., Bordalo, B. D., Pereira, A. M., Ventura, J. and Araújo, J. P., Solid state magnetic refrigerator, Applied Energy, 93 (2012): p. 570-574.

[44]. Silva, D. J., Ventura, J., Araújo, J. P. and Pereira, A. M., Maximizing the temperature span of a solid state active magnetic regenerative refrigerator, Applied Energy, 113 (2014): p. $1149-1154$.

[45]. Vuarnoz, D., Kitanovski, A., Gonin, C., Borgeaud, Y., Delessert, M., Meinen, M. and Egolf, P. W., Quantitative feasibility study of magnetocaloric energy conversion utilizing industrial waste heat, Applied Energy, 100 (2012): p. 229-237.

[46]. Xia, Z., Zhang, Y., Chen, J. and Lin, G., Performance analysis and parametric optimal criteria of an irreversible magnetic Brayton-refrigerator, Applied Energy, 85 (2008): p. 159170 .

[47]. Burdyny, T., Ruebsaat-Trott, A. and Rowe, A., Performance modeling of AMR refrigerators, International Journal of Refrigeration, 37 (2014): p. 51-62.

[48]. Chiba, Y., Smaïli, A., Mahmed, C., Balli, M. and Sari, O., Thermal investigations of an experimental active magnetic regenerative refrigerator operating near room temperature, International Journal of Refrigeration, 37 (2014): p. 36-42.

[49]. Govindaraju, V. R., Vilathgamuwa, D. M. and Ramanujan, R. V., Modelling of a magnetocaloric system for cooling in the kilowatt range, International Journal of Refrigeration, 43 (2014): p. 143-153.

[50]. Nikkola, P., Mahmed, C., Balli, M. and Sari, O., 1D model of an active magnetic regenerator, International Journal of Refrigeration, 37 (2014): p. 43-50.

[51]. Eriksen, D., Engelbrecht, K., Bahl, C. R. H., Bjørk, R., Nielsen, K. K., Insinga, A. R. and Pryds, N., Design and experimental tests of a rotary active magnetic regenerator prototype, International Journal of Refrigeration, 58 (2015): p. 14-21.

[52]. Petersen, T. F., Pryds, N., Smith, A., Hattel, J., Schmidt, H. and Knudsen, H., Twodimensional mathematical model of a reciprocating room-temperature Active Magnetic Regenerator, International Journal of Refrigeration, 31 (2008): p. 432-443.

[53]. Nielsen, K. K., Bahl, C. R. H., Smith, A., Bjork, R., Pryds, N. and Hattel, J., Detailed numerical modeling of a linear parallel-plate Active Magnetic Regenerator, International Journal of Refrigeration, 32 (2009): p. 1478-1486. 
[54]. Nielsen, K. K., Bahl, C. R. H., Smith, A., Pryds, N. and Hattel, J., A comprehensive parameter study of an active magnetic regenerator using a 2D numerical model, International Journal of Refrigeration, 33 (2010): p. 753-764.

[55]. Nielsen, K. K., Smith, A., Bahl, C. R. H. and Olsen, U. L., The influence of demagnetizing effects on the performance of active magnetic regenerators, Journal of Applied Physics, 112 (2012).

[56]. Legait, U., Kedous-Lebouc, A. and Rondot, L., Numerical simulation and analysis of the refrigerant bed behavior using FLUENT software, in proc: 4th IIF-IIR International Conference on Magnetic Refrigeration at Room Temperature, Thermag IV, 2010, Batou, Inner Mongolia, China.

[57]. Liu, M. and Yu, B. F., Numerical investigations on internal temperature distribution and refrigeration performance of reciprocating active magnetic regenerator of room temperature magnetic refrigeration, International Journal of Refrigeration, 34 (2011): p. 617-627.

[58]. Oliveira, P. V., Trevizoli, P. V., Barbosa Jr., J. R. and Prata, A. T., A 2D hybrid model of the fluid flow and heat transfer in a reciprocating active magnetic regenerator, International Journal of Refrigeration, 35 (2012): p. 98-114.

[59]. Lionte, S., Vasile, C. and Siroux, M., Numerical analysis of a reciprocating active magnetic regenerator, Applied Thermal Engineering, 75 (2015): p. 871-879.

[60]. Bouchard, J., Nesreddine, H. and Galanis, N., Model of a porous regenerator used for magnetic refrigeration at room temperature, International Journal of Heat and Mass Transfer, 52 (2009): p. 1223-1229.

[61]. Nielsen, K. K., Tusek, J., Engelbrecht, K., Schopfer, S., Kitanovski, A., Bahl, C. R. H., Smith, A., Pryds, N. and Poredos, A., Review on numerical modeling of active magnetic regenerators for room temperature applications, International Journal of Refrigeration, 34 (2011): p. 603-616.

[62]. Wang, H. S. and Rose, J. W., A theory of film condensation in horizontal non-circular section microchannels, ASME Journal of Heat Transfer, 127 (2005): p. 1096-1105.

[63]. Wang, H. S. and Rose, J. W., Theory of heat transfer during condensation in microchannels, International Journal of Heat and Mass Transfer, 54 (2011): p. 2525-2534.

[64]. Tura, A., Shopfer, S., Rowe, A., Maiorino, A. and Aprea, C., Heat Transfer And Viscous Losses In Micro-Channel Passive Regenerators. Part I - Apparatus And Experimental Results, in proc: 4th IIF-IIR International Conference on Magnetic Refrigeration at Room Temperature, Thermag IV, 2010, Batou, Inner Mongolia, China.

[65]. Morrish, A., The Physical Principles of Magnetism. 1965: John Wiley \& Sons Inc.

[66]. Kays, W. M. and Perkins, H. C., Forced convection, internal flow in ducts, in Handbook of Heat Transfer. 1973: Rohsenow W. M. and Hartnett, J. P., eds., McGraw-Hill, New York.

[67]. Gnielinski, V., New equations for heat and mass transfer in turbulent pipe and channel flow, Int. Chemical Engineering, 16 (1976): p. 359-368.

[68]. Filonenko, G. K., Hydraulic Resistance in Pipes, Teploergetica, 1 (1954): p. 40-44.

[69]. Dupuis, C., Vialle, A. J., Legait, U., Kedous-Lebouc, A. and Ronchetto, D., New Investigations in Magnetic Refrigeration Device, AMR cycle and Refrigerant Bed Performance Evaluation, in proc: 3rd IIF-IIR International Conference on Magnetic Refrigeration at Room Temperature, Thermag III, 2009, Des Moines, Iowa, USA.

[70]. Egolf, P. W., Gravier, L. and Croci, M., High-frequency magnetocaloric modules with heat gates operating with the Peltier effect, in proc: 5th IIF-IIR International Conference on Magnetic Refrigeration at Room Temperature, Thermag V, 2012, Grenoble, France. 


\section{List of table captions}

Table 1 Review of the AMR geometric and operating parameters and the system performance results

Table 2 Summary of the numerical models developed for the magnetic refrigerator [61]

Table 3 Mesh depenance study at $\delta_{x} / d=\delta_{y} / d=1.5, L / d=90, \operatorname{Re}=500, \operatorname{Pr}=7.0$

Table 4 Comparison of present numerical results with experimental data of Dupuis et al. [69] for $\tau=1.4 \mathrm{~s}$.

Table 5 Utilization, mass flow rate and crank radii for case $\mathrm{D}\left(d_{\mathrm{ch}}=1.5 \mathrm{~mm}, \delta=2.5 \mathrm{~mm}, n_{\mathrm{ch}}=88, m_{\mathrm{s}}=337\right.$ $\left.\mathrm{g}, \tau_{\text {flow }}=1.0 \mathrm{~s}, c_{\mathrm{s}}=290 \mathrm{~J} / \mathrm{kg} \mathrm{K}\right)$.

Table 6 Dimensions and parameters for microchannel and parallel-plate regenerators (MCM: Gd; overall dimensions $W=30 \mathrm{~mm}, H=21 \mathrm{~mm}, L=90 \mathrm{~mm}$ )

Table 7 Dimensions and porosities of microchannel regenerators; overall dimensions: $W=30 \mathrm{~mm}, H=21$ $\mathrm{mm}, L=90 \mathrm{~mm}$. 
Table 1 Review of the AMR geometric and operating parameters and the system performance results

\begin{tabular}{|c|c|c|c|c|c|c|c|c|c|}
\hline Research group & Type & Geometry & $\mathrm{MCM}$ & $\begin{array}{l}V_{\text {reg }} \\
\mathrm{cm}^{3}\end{array}$ & $n_{\text {reg }}$ & $\begin{array}{c}f \\
\mathrm{~Hz} \\
\end{array}$ & $\begin{array}{c}\Delta B \\
\mathrm{~T}\end{array}$ & $\begin{array}{c}Q_{\mathrm{c}, \max } \\
\mathrm{W}\end{array}$ & $\begin{array}{c}\Delta T_{\max } \\
\mathrm{K}\end{array}$ \\
\hline $\begin{array}{l}\text { Astronautics } \\
\text { Laboratory, USA } \\
{[2-4]}\end{array}$ & $\begin{array}{l}\text { Reciprocating, } \\
\text { Rotary, } \\
\text { Rotary }\end{array}$ & $\begin{array}{l}\text { Spheres, } \\
\text { Spheres, } \\
\text { Plates }\end{array}$ & $\begin{array}{l}\text { Gd, } \\
\text { (Gd, } \\
\text { GdEr), } \\
\text { Gd }\end{array}$ & $\begin{array}{l}600 \\
33 \\
242\end{array}$ & $\begin{array}{l}2 \\
6 \\
12\end{array}$ & $0.167,4$ & $\begin{array}{l}5 \\
1.5 \\
1.5\end{array}$ & $\begin{array}{l}(100,600) \\
15, \\
(27,0)\end{array}$ & $\begin{array}{l}(38,0), \\
14, \\
(14,25)\end{array}$ \\
\hline $\begin{array}{l}\text { Chubu Electric, } \\
\text { Toshiba, Japan [5] }\end{array}$ & Reciprocating & Spheres & $\mathrm{Gd}$ & 484 & 2 & 0.167 & $\begin{array}{l}4, \\
2\end{array}$ & $\begin{array}{l}100 \\
40\end{array}$ & $\begin{array}{l}26 \\
24\end{array}$ \\
\hline $\begin{array}{l}\text { Institute of Tech., } \\
\text { Chubu, Japan [6] }\end{array}$ & Rotary & Spheres & GdDy & 844 & 4 & $\begin{array}{l}0.39 \\
0.42\end{array}$ & 1.1 & 540 & 0.2 \\
\hline $\begin{array}{l}\text { Nanjing University, } \\
\text { China [7] }\end{array}$ & Reciprocating & Spheres & $\begin{array}{l}\text { Gd, } \\
\text { GdSiGe, } \\
\text { GdDy }\end{array}$ & 200 & 2 & 0.25 & 1.4 & $\begin{array}{l}0, \\
0, \\
(0,40)\end{array}$ & $\begin{array}{l}23 \\
10, \\
(25,5)\end{array}$ \\
\hline $\begin{array}{l}\text { Riso Lab, Denmark } \\
\text { [8-13] }\end{array}$ & Rotary & Spheres & $\mathrm{Gd}$ & 23 & 24 & 2.25 & 1.24 & 200 & 18.9 \\
\hline $\begin{array}{l}\text { POLO Research } \\
\text { Lab, Brazil [14] }\end{array}$ & Reciprocating & Plates & $\mathrm{Gd}$ & 34 & 1 & 0.143 & 1.65 & 3.9 & 4.45 \\
\hline $\begin{array}{l}\text { University of } \\
\text { Victoria, Canada } \\
{[15-19]}\end{array}$ & $\begin{array}{l}\text { Reciprocating, } \\
\text { Rotary }\end{array}$ & $\begin{array}{l}\text { Powder/ } \\
\text { Spheres }\end{array}$ & $\begin{array}{l}\text { Gd, } \\
\text { GdTb, } \\
\text { GdEr, } \\
\text { Gd, } \\
\text { Gd }\end{array}$ & $\begin{array}{l}74, \\
74, \\
74, \\
49, \\
25\end{array}$ & 2 & $\begin{array}{l}1, \\
1, \\
1, \\
0.8,0.6\end{array}$ & 2 & $\begin{array}{l}0, \\
0, \\
0, \\
0, \\
7\end{array}$ & $\begin{array}{l}50, \\
50, \\
50, \\
15.5, \\
14\end{array}$ \\
\hline $\begin{array}{l}\text { University of } \\
\text { Ljubljana, Slovenia } \\
{[21-23]}\end{array}$ & Reciprocating & $\begin{array}{l}\text { Plates, } \\
\text { Cylinders, } \\
\text { Powder, } \\
\text { Spheres }\end{array}$ & $\begin{array}{l}\mathrm{LaFeCoSi}, \\
\mathrm{Gd}\end{array}$ & 32 & 1 & $\begin{array}{l}0.15- \\
0.45\end{array}$ & 1.15 & 0 & 23 \\
\hline $\begin{array}{l}\text { University of } \\
\text { Salerno, Italy [24] }\end{array}$ & Rotary & Particles & $\mathrm{Gd}$ & 31.5 & 8 & $\begin{array}{l}0.36- \\
1.79\end{array}$ & 1.25 & 0 & 13.5 \\
\hline $\begin{array}{l}\text { G2E Lab, } \\
\text { Grenoble, France } \\
\text { [27] }\end{array}$ & Reciprocating & Plates & $\begin{array}{l}\mathrm{Gd} \\
\mathrm{PrSrMnO}_{3} \\
\mathrm{LaFeCoSi}\end{array}$ & $\begin{array}{l}14 \\
21 \\
24\end{array}$ & 1 & $\begin{array}{l}0.1- \\
1.43\end{array}$ & 0.8 & 0 & $\begin{array}{l}11.5 \\
10.5 \\
5\end{array}$ \\
\hline $\begin{array}{l}\text { University of } \\
\text { Tokyo, Japan [29] }\end{array}$ & Reciprocating & Particles & $\mathrm{Gd}$ & - & 1 & 0.25 & 1.07 & 0 & 6.5 \\
\hline $\begin{array}{l}\text { Wroclaw Uni. of } \\
\text { Technology, } \\
\text { Poland [30] }\end{array}$ & Reciprocating & Particles & $\mathrm{Gd}$ & - & 1 & 0.025 & 1.0 & 0 & 1.6 \\
\hline
\end{tabular}


Table 2 Summary of the numerical models developed for the magnetic refrigerator [61]

\begin{tabular}{|c|c|c|c|c|c|c|c|}
\hline Authors & Geometry & $\mathrm{MCM}$ & MCE method & $\begin{array}{c}c_{\mathrm{MCM}} \\
\text { dependence }\end{array}$ & Fluid & $\begin{array}{l}\text { Axial } \\
\text { Cond. }\end{array}$ & $\begin{array}{c}\text { Pressure } \\
\text { drop }\end{array}$ \\
\hline \multicolumn{8}{|l|}{$1 D$ models } \\
\hline Siddikov et al. [35] & Particles & $\mathrm{Gd}$ & Source term & $T, B$ & - & $\checkmark$ & $\checkmark$ \\
\hline Dikeos et al. [36] & Particles & $\begin{array}{c}\mathrm{Gd}, \\
\mathrm{DyAl}_{2}\end{array}$ & Temp. jump & $T, B$ & Helium & $\checkmark$ & $x$ \\
\hline Kawanami et al. [41] & Chips & Gd & Temp. jump & Constant & $\begin{array}{l}\text { Air, } \\
\text { water }\end{array}$ & $\checkmark$ & $x$ \\
\hline Engelbrecht $[37,38]$ & $\begin{array}{l}\text { Particles, } \\
\text { plates }\end{array}$ & various & Source term & $T, B$ & Water & $\checkmark$ & $\checkmark$ \\
\hline Aprea et al. [39] & Particles & $\mathrm{Gd}, \mathrm{Tb}$ & Temp. jump & - & Water & $x$ & $x$ \\
\hline Tagliafico et al. [40] & Particles & Gd & Source term & $T, B$ & Water & $\checkmark$ & $x$ \\
\hline Tusek et al. [21] & Spheres & $\mathrm{Gd}$ & Temp. jump & $T, B$ & Water & $\checkmark$ & $\checkmark$ \\
\hline Burdyny et al. [47] & Sphere & Gd & - & Constant & $\begin{array}{l}\text { Water- } \\
\text { Glycol }\end{array}$ & - & - \\
\hline Chiba et al. [48] & Plates & $\mathrm{Gd}$ & Temp. jump & $T, B$ & Water & $\checkmark$ & $\checkmark$ \\
\hline Nikkola et al. [50] & Plates & $\mathrm{Gd}$ & Temp. jump & $T, B$ & Water & $\checkmark$ & $\checkmark$ \\
\hline \multicolumn{8}{|l|}{ 2D models } \\
\hline Petersen et al. [52] & Plates & Gd & Temp. jump & $T, B$ & Water & $\checkmark$ & $\checkmark$ \\
\hline Nielsen et al. [53] & Plates & $\mathrm{Gd}$ & $\begin{array}{l}\text { Temp. jump, } \\
\text { Source term }\end{array}$ & $T, B$ & Water & $\checkmark$ & $\checkmark$ \\
\hline Legait et al. [56] & Plates & Gd & Temp. jump & constant & Water & $\checkmark$ & $\checkmark$ \\
\hline Liu and $\mathrm{Yu}$ [57] & Particles & Gd & Source term & $T, B$ & Water & $\checkmark$ & $\checkmark$ \\
\hline Oliveira et al. [58] & Plates & $\mathrm{Gd}$ & Temp. jump & $T, B$ & Water & $\checkmark$ & $\checkmark$ \\
\hline Lionte et al. [59] & Plates & $\mathrm{Gd}$ & Source term & $T, B$ & Water & $\checkmark$ & $\checkmark$ \\
\hline \multicolumn{8}{|l|}{ 3D models } \\
\hline Bouchard et al. [56] & Particles & $\mathrm{Gd}$ & Temp. jump & $T, B$ & Water & $\checkmark$ & $\checkmark$ \\
\hline
\end{tabular}


Table 3 Mesh depenance study at $\delta_{x} / d=\delta_{y} / d=1.5, L / d=90, \operatorname{Re}=500, \operatorname{Pr}=7.0$

\begin{tabular}{ccccc}
\hline$n_{\Delta x}$ & $n_{\Delta y}$ & $n_{\Delta z}$ & $n_{\mathrm{CV}}$ & $N u_{\mathrm{av}}$ \\
\hline 8 & 8 & 60 & 24480 & 5.71 \\
8 & 8 & 90 & 36720 & 5.70 \\
8 & 8 & 120 & 46080 & 5.58 \\
8 & 8 & 150 & 57600 & 5.59 \\
10 & 10 & 60 & 37200 & 5.59 \\
\hdashline 10 & 10 & 90 & 55800 & 5.57 \\
\hline 10 & 10 & 120 & 74400 & 5.55 \\
10 & 10 & 150 & 93000 & 5.64 \\
15 & 15 & 60 & 48960 & 5.59 \\
15 & 15 & 90 & 73440 & 5.57 \\
15 & 15 & 120 & 97920 & 5.55 \\
15 & 15 & 150 & 122400 & 5.54 \\
\hline
\end{tabular}


Table 4 Comparison of present numerical results with experimental data of Dupuis et al. [69] for $\tau=1.4 \mathrm{~s}$.

\begin{tabular}{cccc}
\hline$m_{\mathrm{r}}$ & $\Delta T_{\mathrm{r}, \exp }$ & $\Delta T_{\mathrm{r}, \text { num }}$ & $\varepsilon$ \\
$\mathrm{g} / \mathrm{s}$ & $\mathrm{K}$ & $\mathrm{K}$ & $\%$ \\
\hline 1 & 9.5 & 11.0 & 14 \\
2 & 10.0 & 11.0 & 10 \\
4 & 8.0 & 9.0 & 11 \\
\hline
\end{tabular}


Table 5 Utilization, mass flow rate and crank radii for case $\mathrm{D}\left(d_{\mathrm{ch}}=1.5 \mathrm{~mm}, \delta=2.5 \mathrm{~mm}, n_{\mathrm{ch}}=88, m_{\mathrm{s}}=337\right.$ $\left.\mathrm{g}, \tau_{\text {flow }}=1.0 \mathrm{~s}, c_{\mathrm{s}}=290 \mathrm{~J} / \mathrm{kg} \mathrm{K}\right)$.

\begin{tabular}{cccccccccc}
\hline Parameter & \multicolumn{10}{c}{ Value } \\
\hline$\varphi$ & 0.05 & 0.1 & 0.2 & 0.3 & 0.4 & 0.5 & 0.6 & 0.7 & 0.8 \\
$m_{\mathrm{r}, \mathrm{av}} /(\mathrm{g} / \mathrm{s})$ & 1.17 & 2.34 & 4.68 & 7.02 & 9.36 & 11.7 & 14.04 & 16.38 & 18.72 \\
$R / \mathrm{mm}$ & 2.9 & 5.8 & 11.6 & 17.4 & 23.2 & 29.0 & 34.8 & 40.6 & 46.4 \\
\hline
\end{tabular}


Table 6 Dimensions and parameters for microchannel and parallel-plate regenerators (MCM: Gd; overall dimensions $W=30 \mathrm{~mm}, H=21 \mathrm{~mm}, L=90 \mathrm{~mm}$ )

\begin{tabular}{ccccccccccc}
\hline \multirow{2}{*}{ Type } & Case & $\begin{array}{c}d_{\mathrm{ch}} \\
\mathrm{mm}\end{array}$ & $\begin{array}{c}\delta_{\mathrm{ch}} \\
\mathrm{mm}\end{array}$ & $\begin{array}{c}\delta_{\mathrm{s}} \\
\mathrm{mm}\end{array}$ & $\begin{array}{c}\delta_{\mathrm{f}} \\
\mathrm{mm}\end{array}$ & $\begin{array}{c}n_{\mathrm{ch}} \\
\text { Microchannel }\end{array}$ & $\begin{array}{c}d_{\mathrm{h}} \\
\mathrm{mm}\end{array}$ & $\varepsilon$ & $\begin{array}{c}a_{\mathrm{p}} \\
\mathrm{m}^{2} / \mathrm{m}^{3}\end{array}$ & $\begin{array}{c}m_{\mathrm{s}} \\
\mathrm{g}\end{array}$ \\
\hline & $\mathrm{A}$ & 1.0 & 1.2 & - & - & 400 & 1.0 & 0.50 & 1995 & 225 \\
& $\mathrm{~B}$ & 1.5 & 1.7 & - & - & 176 & 1.5 & 0.50 & 1316 & 227 \\
& $\mathrm{C}$ & 2.0 & 2.2 & - & - & 117 & 2.0 & 0.58 & 1167 & 187 \\
& $\mathrm{D}$ & 1.5 & 2.5 & - & - & 88 & 1.5 & 0.25 & 658 & 337 \\
& $\mathrm{E}$ & 2.0 & 2.5 & - & - & 96 & 2.0 & 0.48 & 957 & 233 \\
& $\mathrm{~F}$ & 0.5 & 0.7 & - & - & 1250 & 0.5 & 0.39 & 3117 & 273 \\
\multirow{2}{*}{ Parallel-plate } & $\mathrm{G}$ & 1.0 & 1.5 & - & - & 280 & 1.0 & 0.35 & 1400 & 290 \\
& $\mathrm{H}$ & - & - & 0.25 & 0.43 & 31 & 0.5 & 0.37 & 2952 & 288 \\
& $\mathrm{I}$ & - & - & 0.50 & 0.85 & 16 & 1.0 & 0.38 & 1524 & 277 \\
\hline
\end{tabular}


Table 7 Dimensions and porosities of microchannel regenerators; overall dimensions: $W=30 \mathrm{~mm}, H=21$ $\mathrm{mm}, L=90 \mathrm{~mm}$.

\begin{tabular}{|c|c|c|c|}
\hline $\begin{array}{r}d_{\mathrm{ch}} \\
\mathrm{mm}\end{array}$ & $\begin{array}{c}\delta_{\mathrm{ch}} \\
\mathrm{mm}\end{array}$ & $n_{\mathrm{ch}}$ & $\varepsilon$ \\
\hline \multirow{7}{*}{1.0} & 3.0 & 70 & 0.087 \\
\hline & 2.5 & 77 & 0.096 \\
\hline & 2.0 & 126 & 0.157 \\
\hline & 1.5 & 228 & 0.284 \\
\hline & 1.2 & 285 & 0.355 \\
\hline & 1.2 & 400 & 0.499 \\
\hline & 1.1 & 500 & 0.623 \\
\hline \multirow{9}{*}{1.5} & 4.0 & 35 & 0.098 \\
\hline & 3.5 & 40 & 0.112 \\
\hline & 3.0 & 54 & 0.151 \\
\hline & 3.0 & 77 & 0.216 \\
\hline & 2.5 & 88 & 0.247 \\
\hline & 2.0 & 126 & 0.353 \\
\hline & 1.7 & 176 & 0.049 \\
\hline & 1.7 & 200 & 0.561 \\
\hline & 1.6 & 216 & 0.606 \\
\hline \multirow{8}{*}{2.0} & 4.5 & 25 & 0.125 \\
\hline & 4.0 & 35 & 0.175 \\
\hline & 3.5 & 48 & 0.239 \\
\hline & 3.0 & 70 & 0.349 \\
\hline & 3.0 & 77 & 0.384 \\
\hline & 2.5 & 96 & 0.479 \\
\hline & 2.2 & 104 & 0.519 \\
\hline & 2.2 & 117 & 0.583 \\
\hline
\end{tabular}




\section{List of figure captions}

Fig. 1 Schematic of the magnetic refrigerator

Fig. 2 Overall and channel dimensions of the microchannel regenerator

Fig. 3 Simulation model of the magnetic refrigerator

Fig. 4 Variation of $\Delta T_{\text {ad }}$ with $T_{\mathrm{S}}$ predicted by the mean field model (Morrish [65])

Fig. 5 Schematic of the fluid displacer (coldend piston chamber shown)

Fig. 6 Variations of (a) $m_{\mathrm{r}}$, (b) $B_{\exp }$ and (c) $B_{\text {num }}$ with time $t$

Fig. 7 Flow chart of the solving scheme

Fig. 8 Grid for a single microchannel

Fig. 9 Overall and channel dimensions of the parallel plate regenerator

Fig. 10 Comparison of the present simulation results with experimental data of Dupuis et al. [69]. (a) $\tau_{\text {flow }}=$ $0.7 \mathrm{~s}, m_{\mathrm{r}}=2.0 \mathrm{~g} / \mathrm{s} ;$; (b) $\tau_{\text {flow }}=1.4 \mathrm{~s}, m_{\mathrm{r}}=1.0 \mathrm{~g} / \mathrm{s}$.

Fig. 11 (a) No load temperature span across two ends of microchannel regenerator for case $\mathrm{A} ; \varphi=0.1, \Delta B=$ $0.8 \mathrm{~T}$ and $f=2.0 \mathrm{~Hz}$; (b) Variation of no-load temperature span of microchannel regenerator with utilization $\varphi$, for case $\mathrm{A}, \Delta B=0.8 \mathrm{~T}$ and $f=0.5 \mathrm{~Hz}$.

Fig. 12 Variation of cooling capacity $Q_{\mathrm{C}}$ with utilization $\varphi$ for (a) different frequencies for microchannel regenerator case B and (b) three microchannel regenerator cases A, B and C (see Table 6). The solid line is a guide for the eye.

Fig. 13 Variation of cooling capacity $Q_{\mathrm{C}}$ with porosity $\varepsilon$ for various dimensions of microchannel regenerator (see Table 7). The solid line is a guide for the eye.

Fig. 14 Variation of cooling capacity $Q_{\mathrm{C}}$ with cycle frequency $f$ for microchannel regenerator cases $\mathrm{A}, \mathrm{D}$ and E (see Table 6).

Fig. 15 Variation of $\Delta T_{\text {ad }}$ with MCM temperature for $\Delta B$ values of $0.8,1.0,1.2,1.4$ and $1.6 \mathrm{~T}$, predicted by the mean field model for $\mathrm{Gd}$.

Fig. 16 Variation of (a) no-load temperature span and (b) cooling capacity with magnetic field intensity change for microchannel regenerator case A (see Table 6).

Fig. 17 Different temperature spans defined in a magnetic refrigerator.

Fig. 18 Variation of cooling capacity with imposed temperature span for microchannel regenerator case A (see Table 6).

Fig. 19 Effect of mass flow rate profile. (a) two profiles of mass flow rate and (b) variation of cooling capacity with utilization for two profiles of mass flow rate. Microchannel regenerator cases A and B (see Table 6). The solid line is a guide for the eye.

Fig. 20 Comparison of the performance for two microchannel and two parallel-plate regenerators (see Table 6). (a) cooling capacity; (b) cooling capacity per unit pumping power. The solid line is a guide for the eye. 


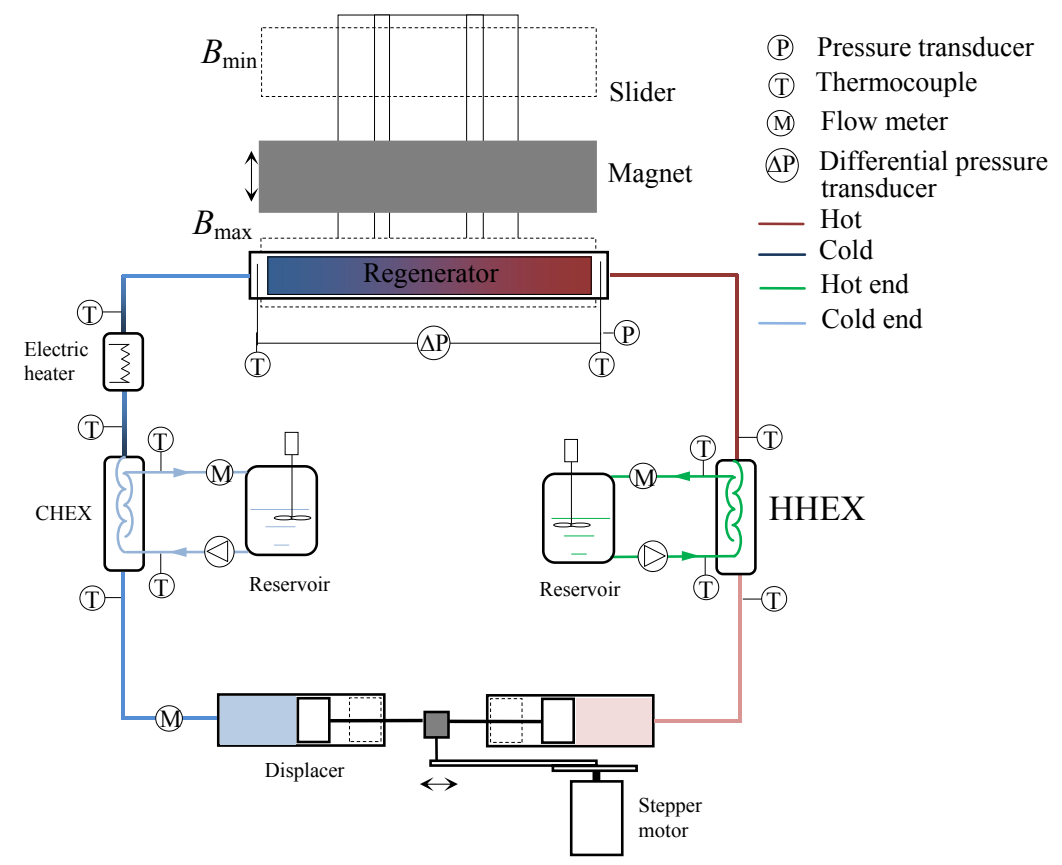

Fig. 1 Schematic of the magnetic refrigerator 


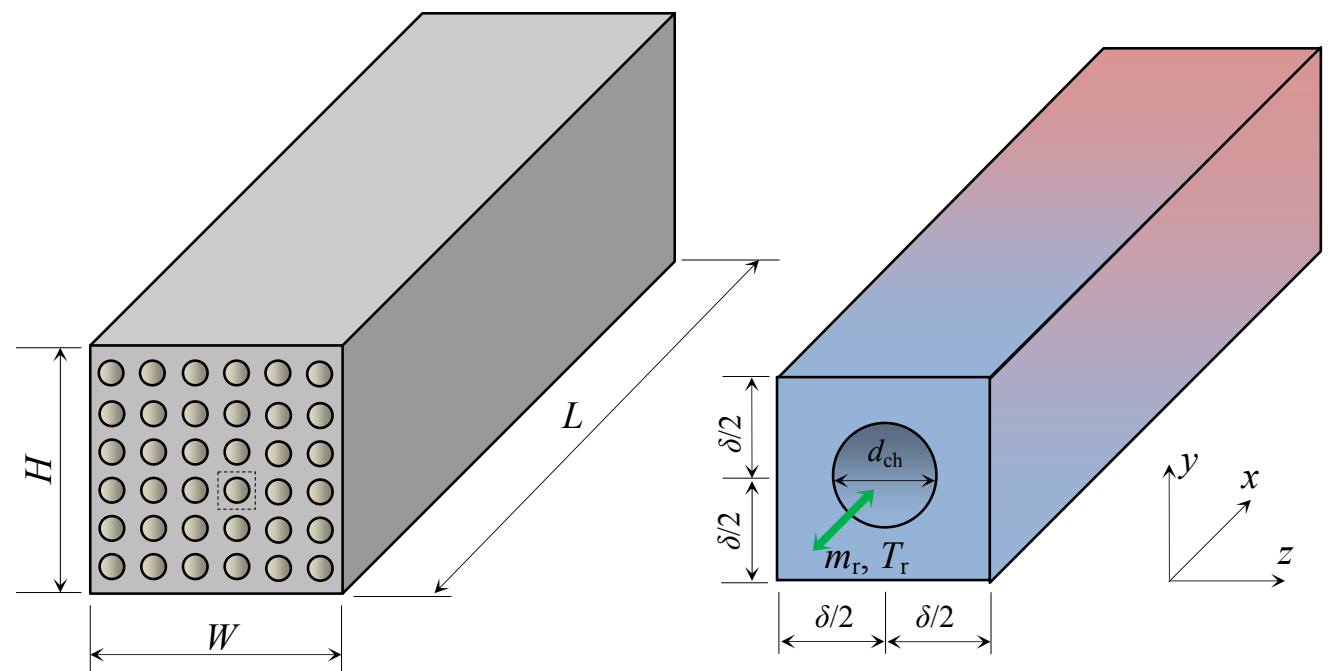

(a)

(b)

Fig. 2 Overall and channel dimensions of the microchannel regenerator 


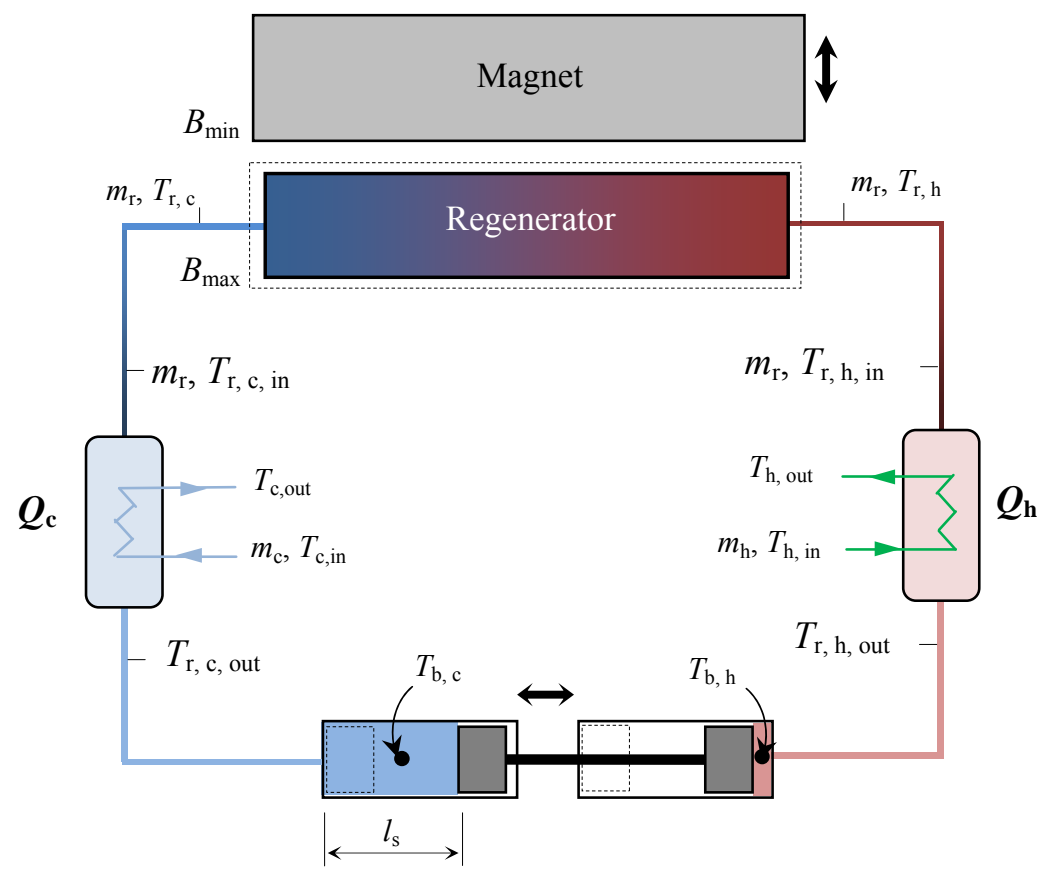

Fig. 3 Simulation model of the magnetic refrigerator 


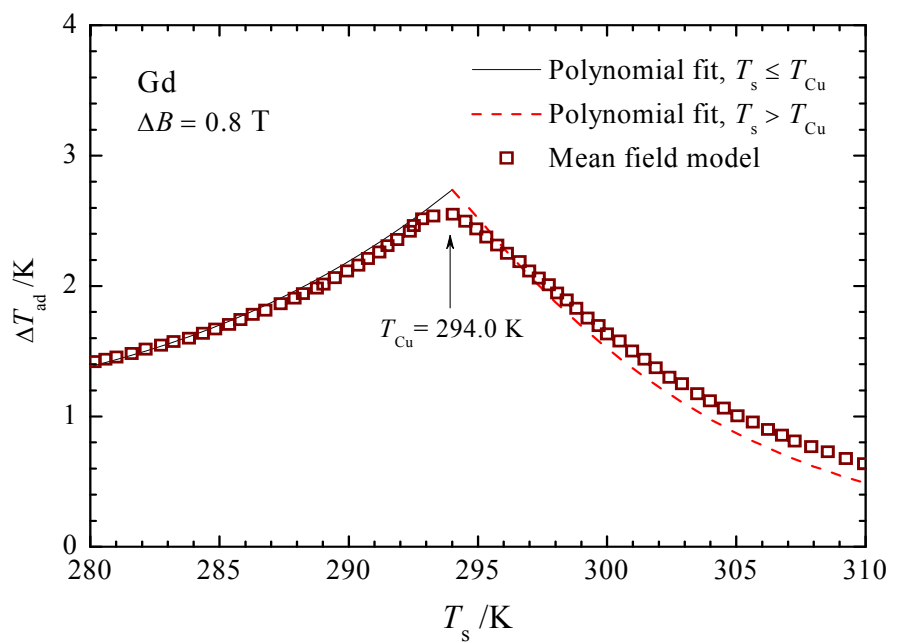

Fig. 4 Variation of $\Delta T_{\text {ad }}$ with $T_{\mathrm{S}}$ predicted by the mean field model (Morrish [65]) 


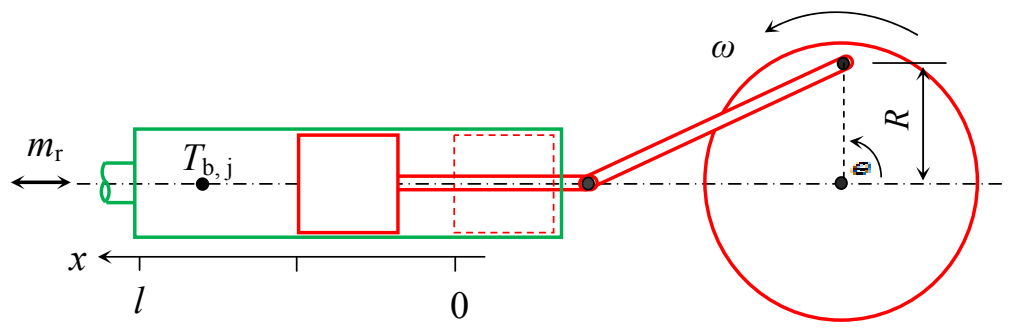

Fig. 5 Schematic of the fluid displacer (coldend piston chamber shown) 


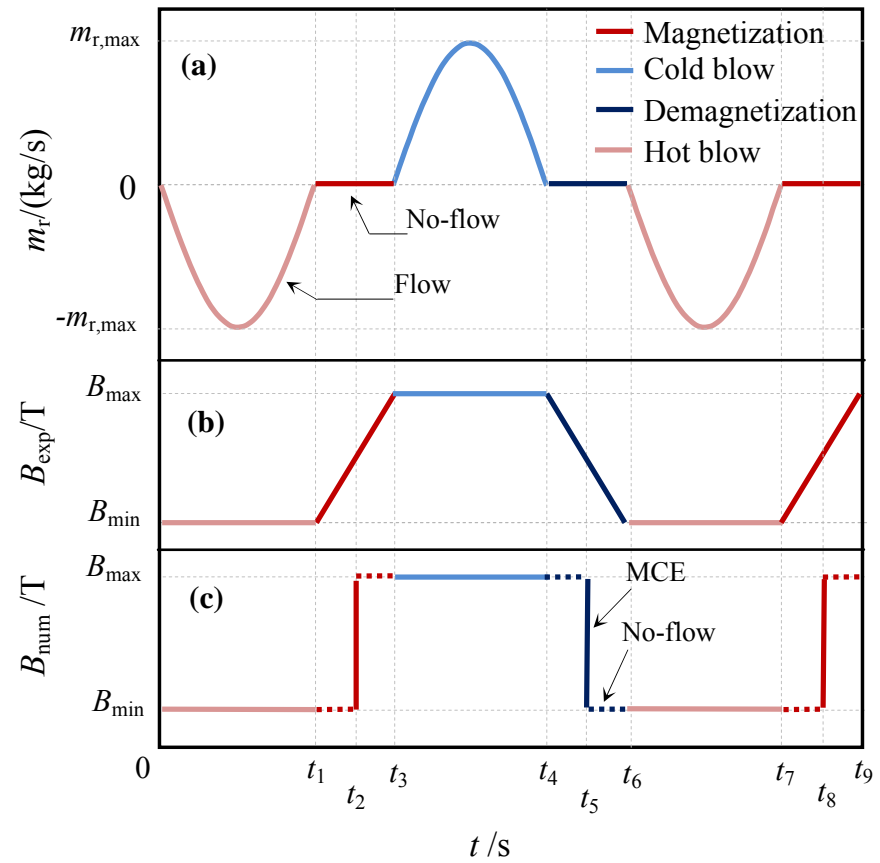

Fig. 6 Variations of (a) $m_{\mathrm{r}}$, (b) $B_{\text {exp }}$ and (c) $B_{\text {num }}$ with time $t$ 


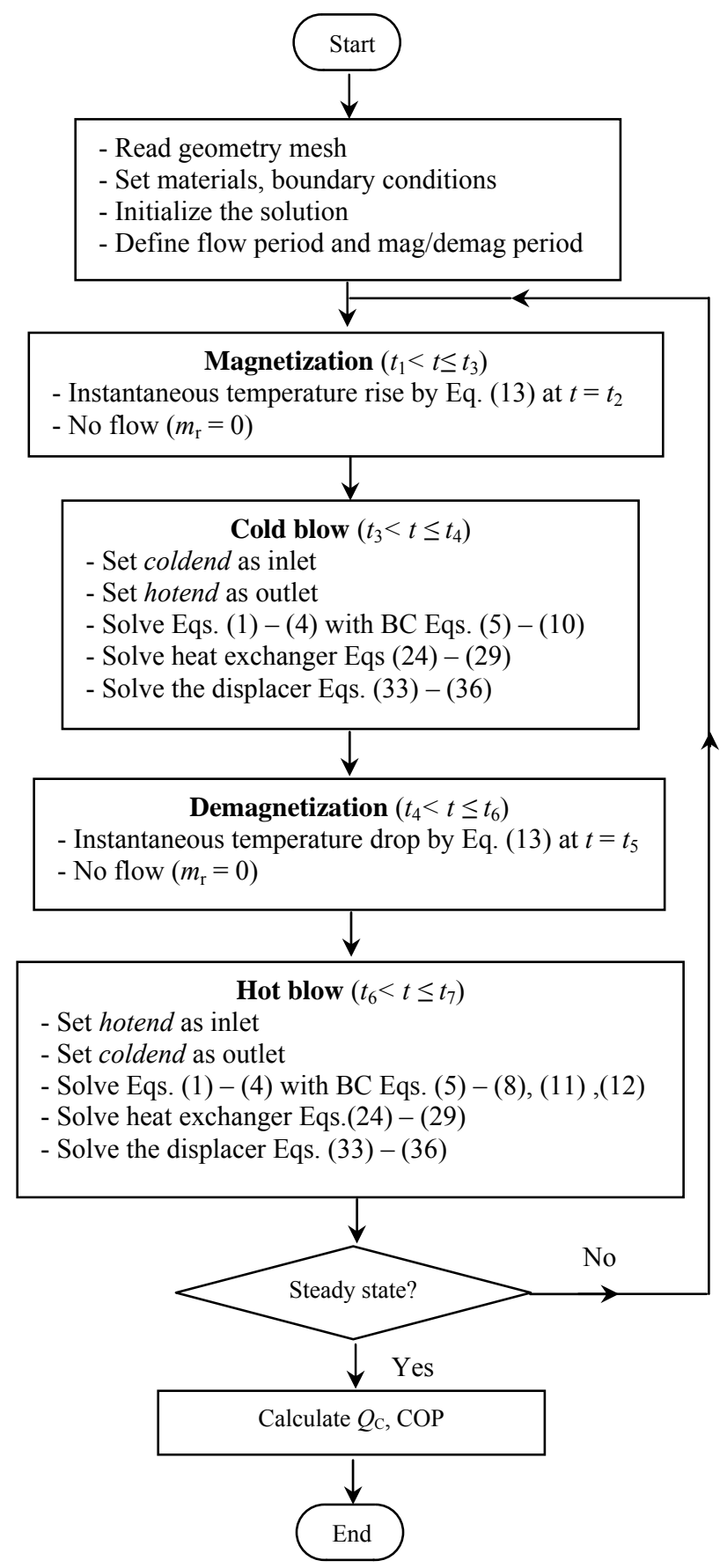

Fig. 7 Flow chart of the solving scheme 

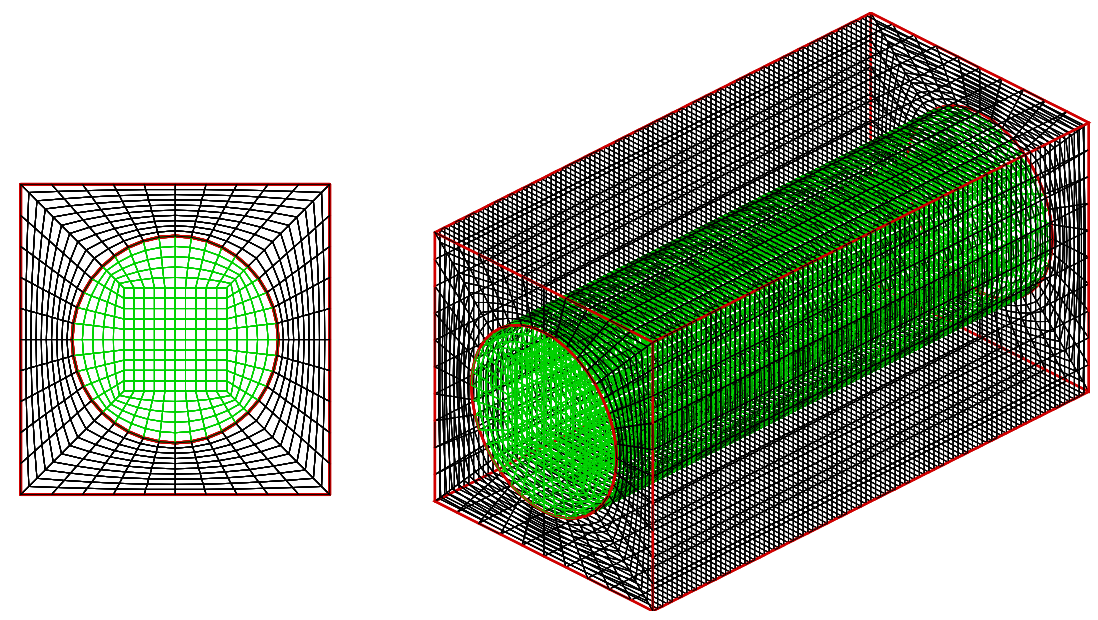

Fig. 8 Grid for a single microchannel 


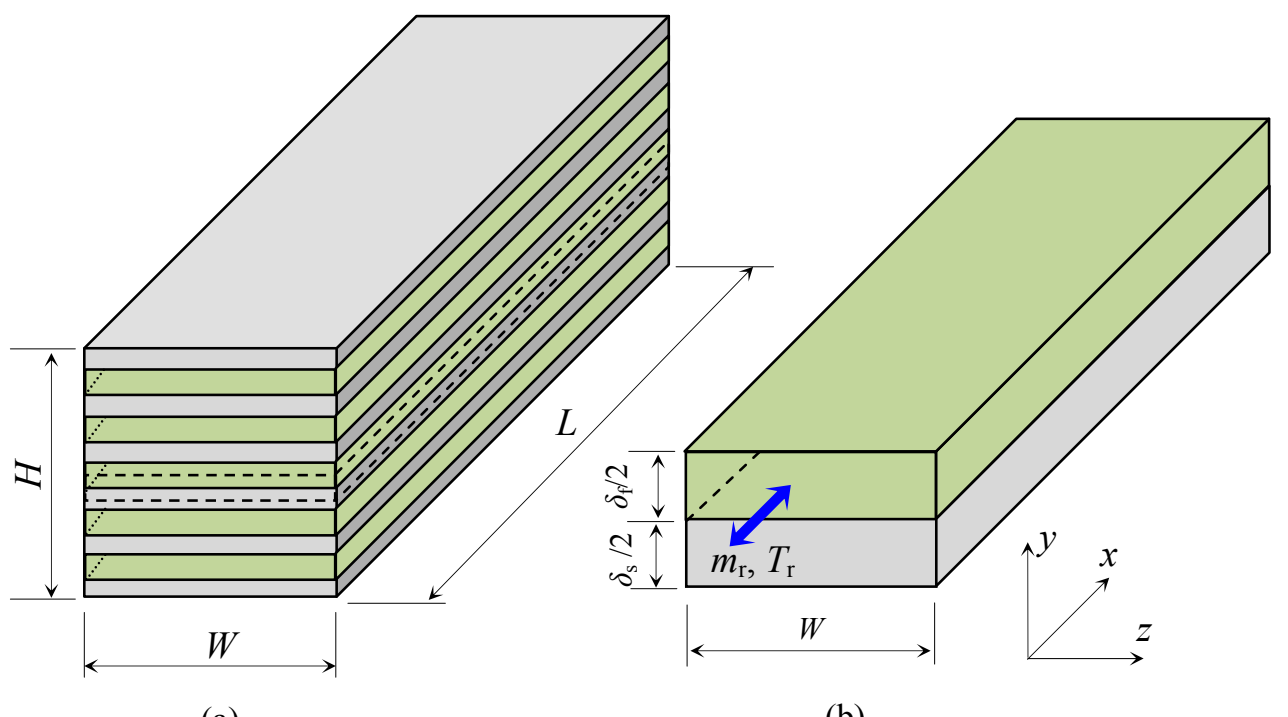

(a)

(b)

Fig. 9 Overall and channel dimensions of the parallel plate regenerator 

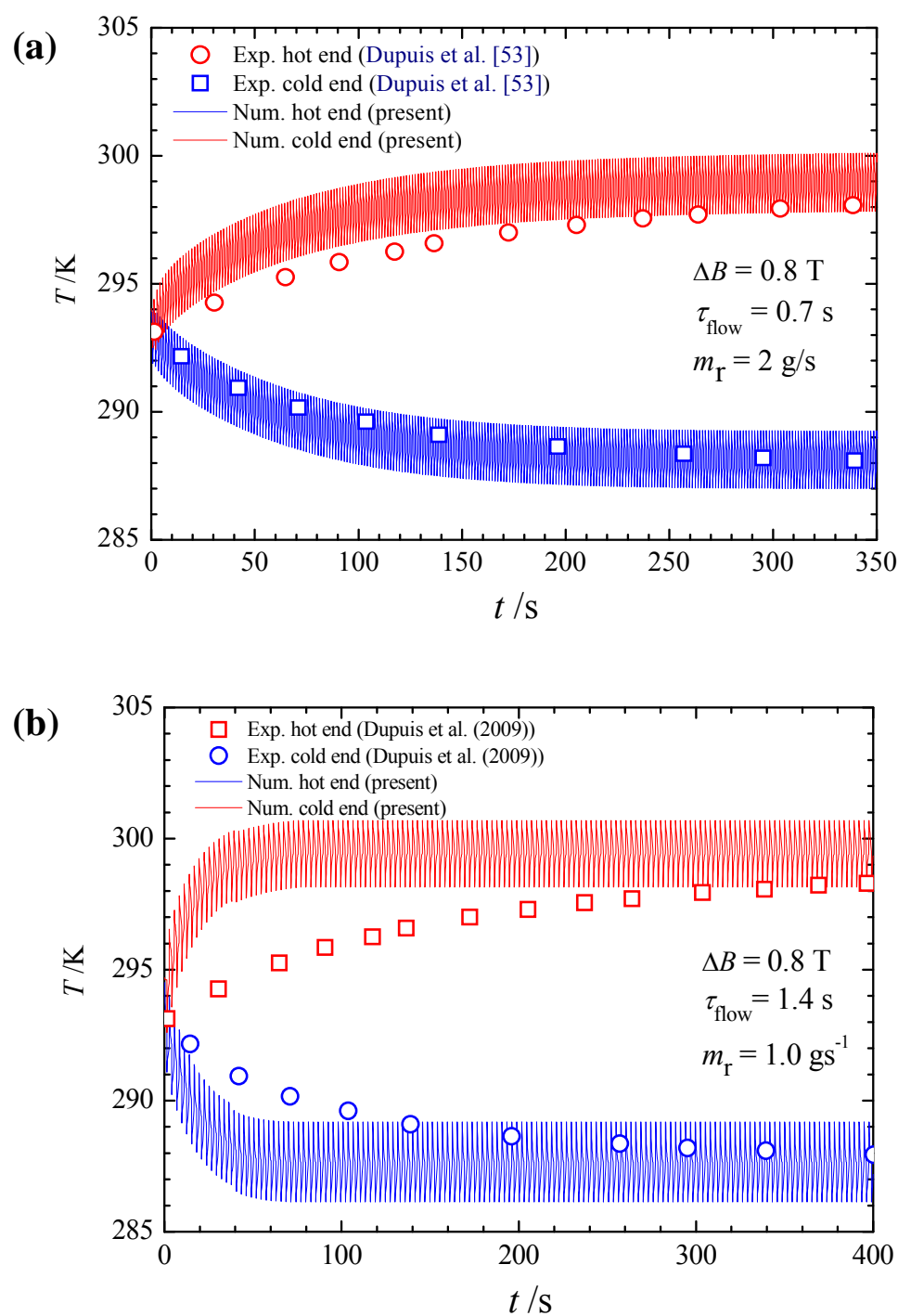

Fig. 10 Comparison of the present simulation results with experimental data of Dupuis et al. [69]. (a) $\tau_{\text {flow }}=$ $0.7 \mathrm{~s}, m_{\mathrm{r}}=2.0 \mathrm{~g} / \mathrm{s} ;$ (b) $\tau_{\text {flow }}=1.4 \mathrm{~s}, m_{\mathrm{r}}=1.0 \mathrm{~g} / \mathrm{s}$. 
(a)

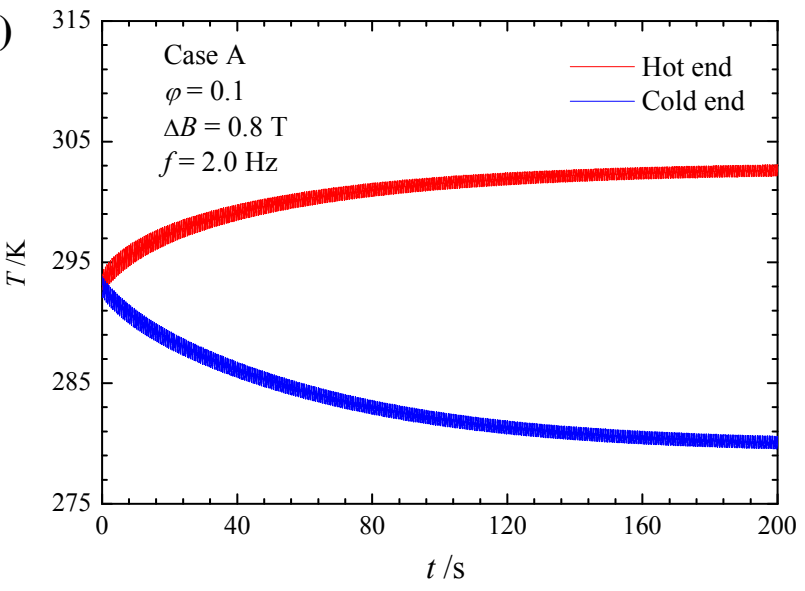

(b)

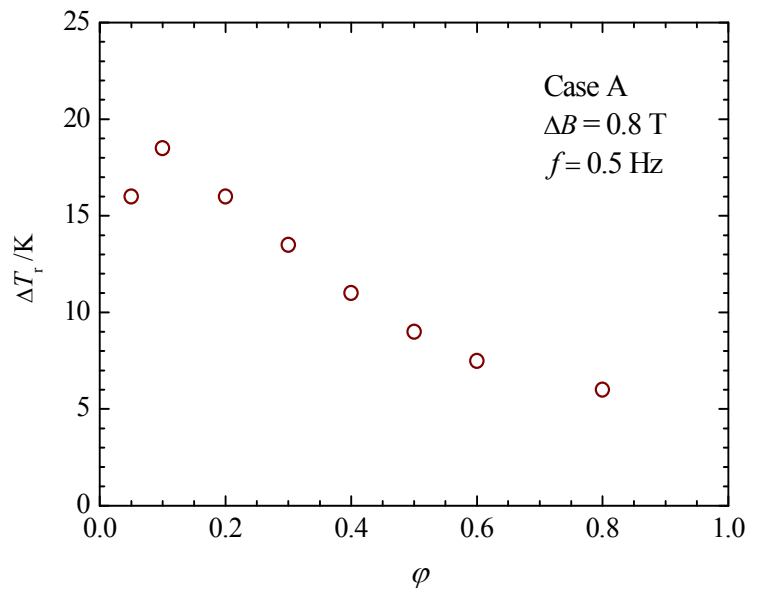

Fig. 11 (a) No load temperature span across two ends of microchannel regenerator for case $\mathrm{A} ; \varphi=0.1, \Delta B=$ $0.8 \mathrm{~T}$ and $f=2.0 \mathrm{~Hz}$; (b) Variation of no-load temperature span of microchannel regenerator with utilization $\varphi$, for case $\mathrm{A}, \Delta B=0.8 \mathrm{~T}$ and $f=0.5 \mathrm{~Hz}$. 

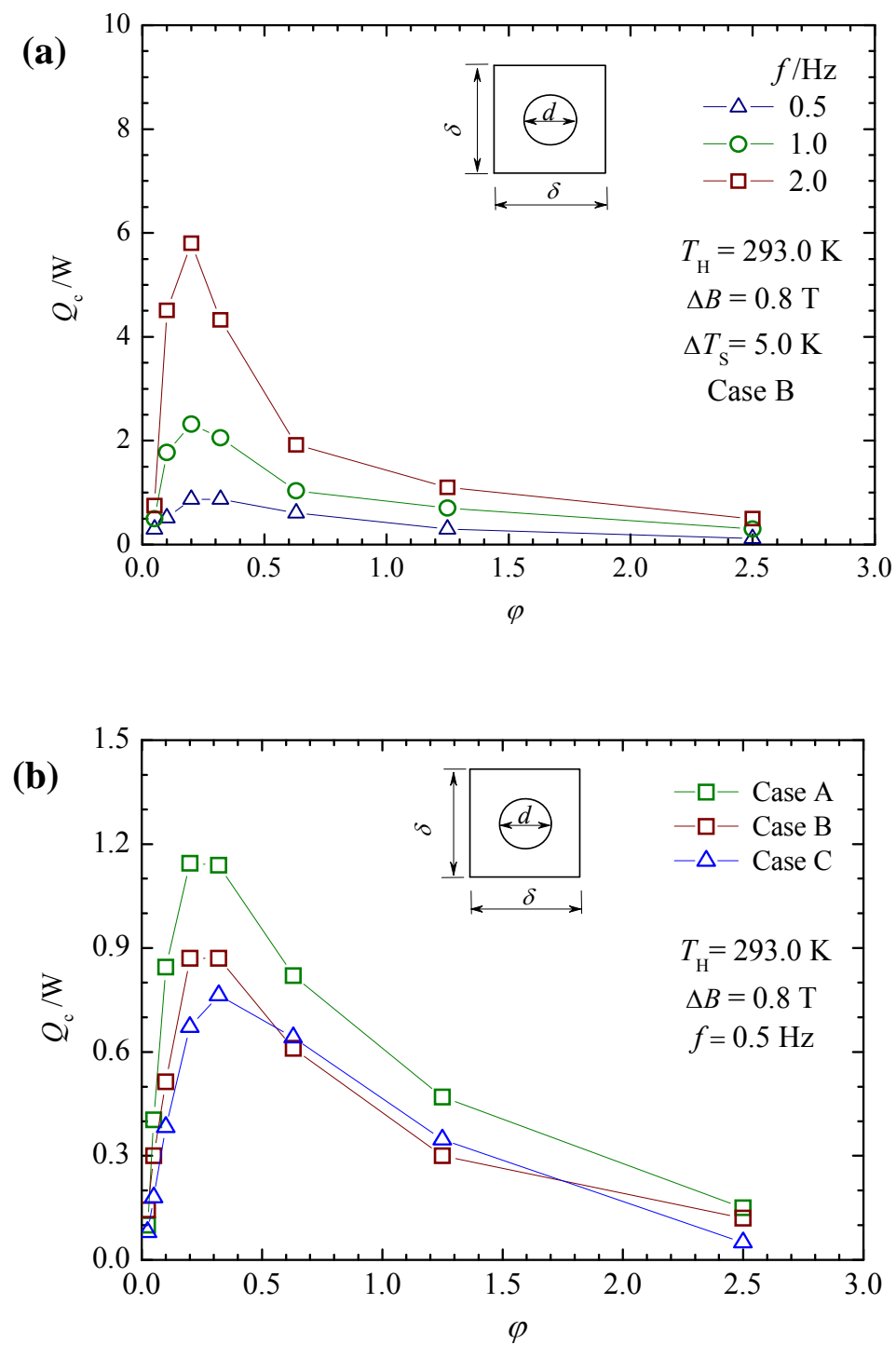

Fig. 12 Variation of cooling capacity $Q_{\mathrm{C}}$ with utilization $\varphi$ for (a) different frequencies for microchannel regenerator case B and (b) three microchannel regenerator cases A, B and C (see Table 6). The solid line is a guide for the eye. 


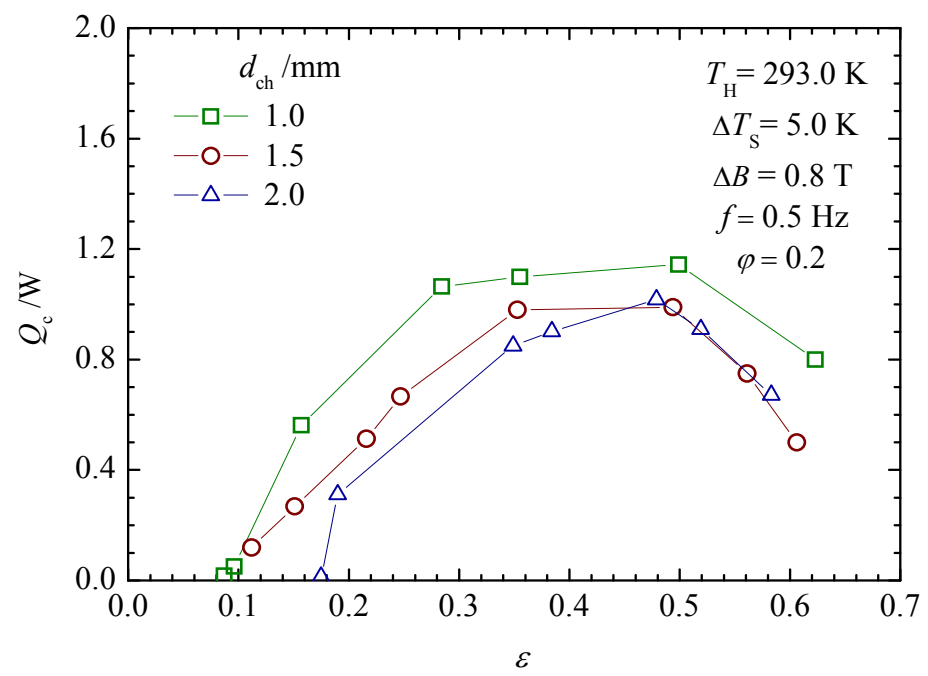

Fig. 13 Variation of cooling capacity $Q_{\mathrm{C}}$ with porosity $\varepsilon$ for various dimensions of microchannel regenerator (see Table 7). The solid line is a guide for the eye. 


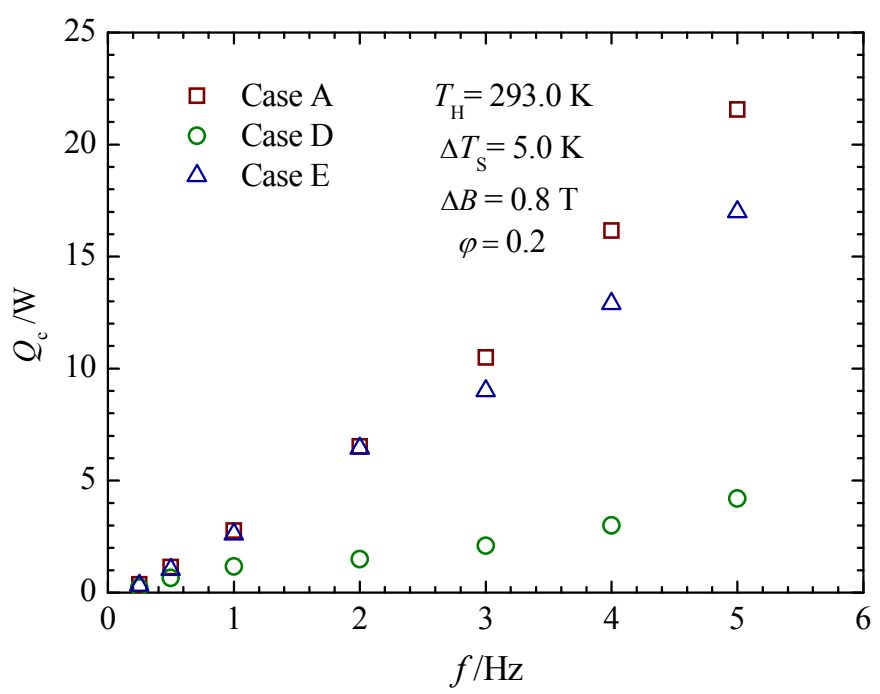

Fig. 14 Variation of cooling capacity $Q_{\mathrm{C}}$ with cycle frequency $f$ for microchannel regenerator cases A, D and E (see Table 6). 


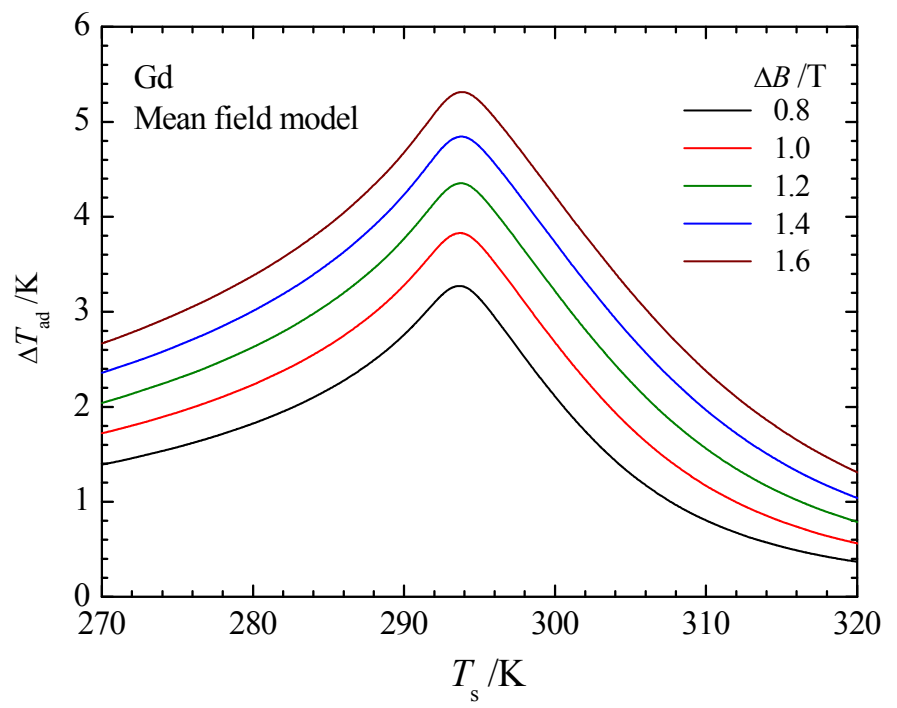

Fig. 15 Variation of $\Delta T_{\text {ad }}$ with MCM temperature for $\Delta B$ values of $0.8,1.0,1.2,1.4$ and $1.6 \mathrm{~T}$, predicted by the mean field model for Gd. 

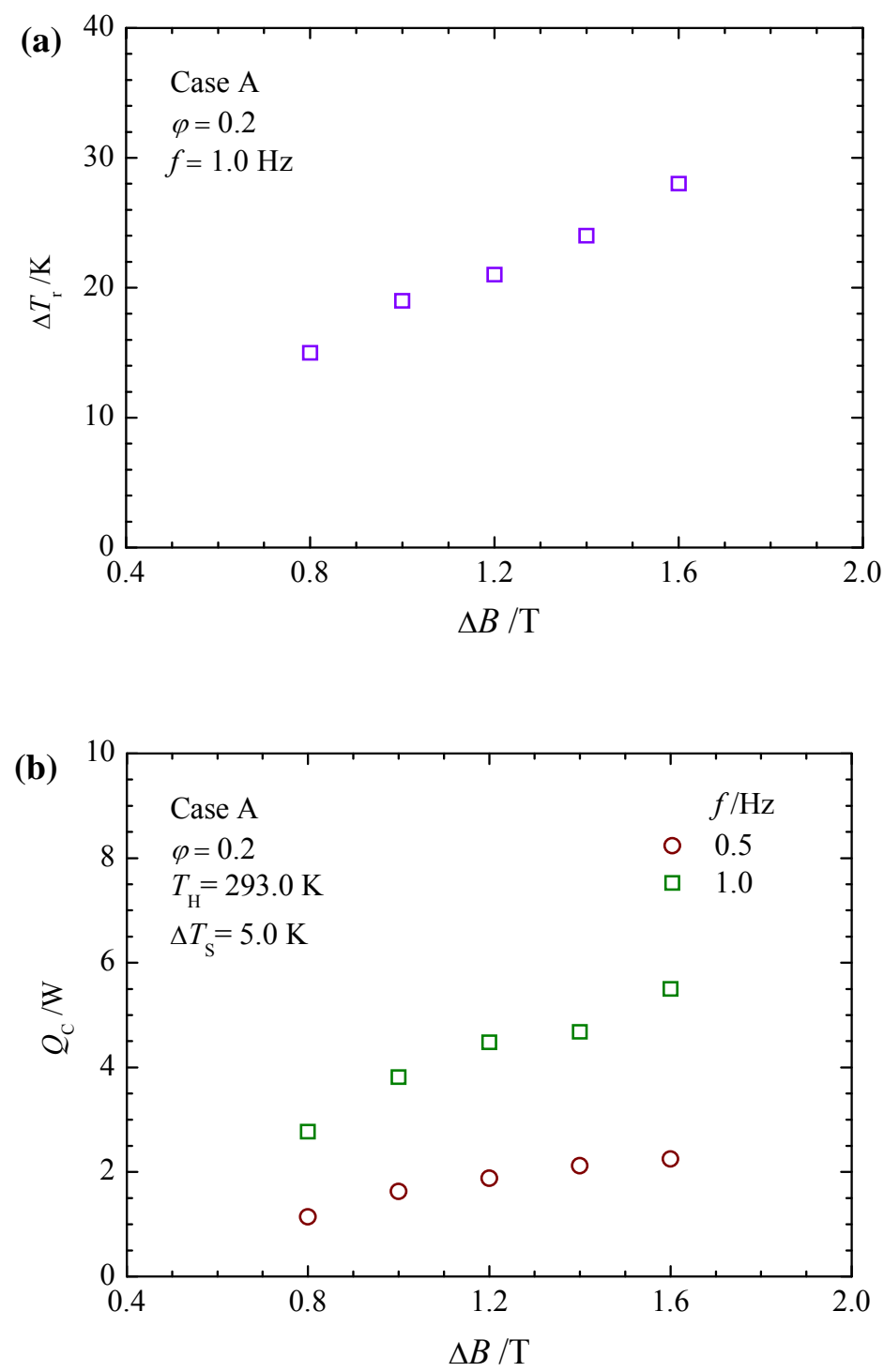

Fig. 16 Variation of (a) no-load temperature span and (b) cooling capacity with magnetic field intensity change for microchannel regenerator case A (see Table 6). 


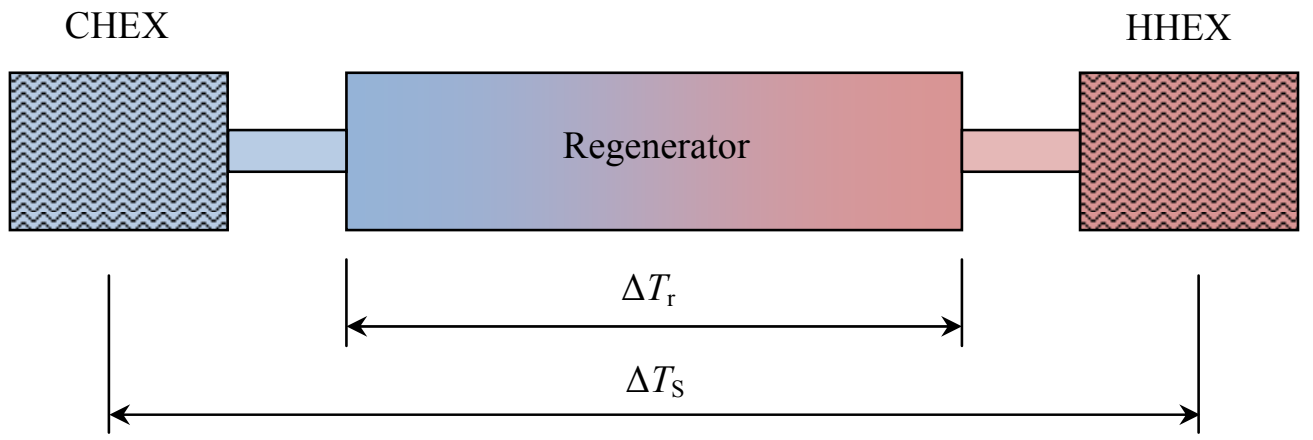

Fig. 17 Different temperature spans defined in a magnetic refrigerator. 


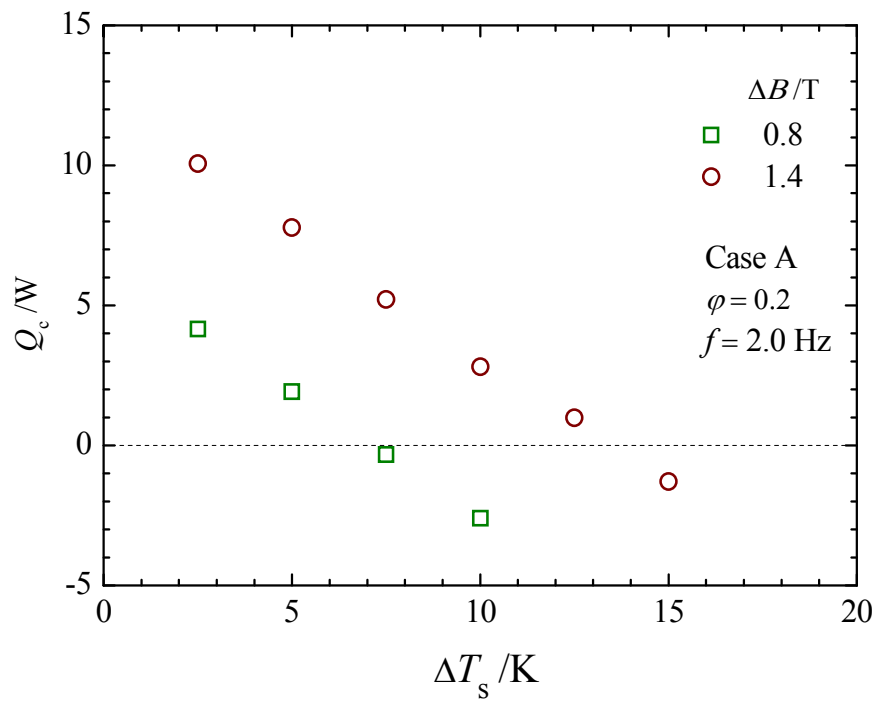

Fig. 18 Variation of cooling capacity with imposed temperature span for microchannel regenerator case A (see Table 6). 

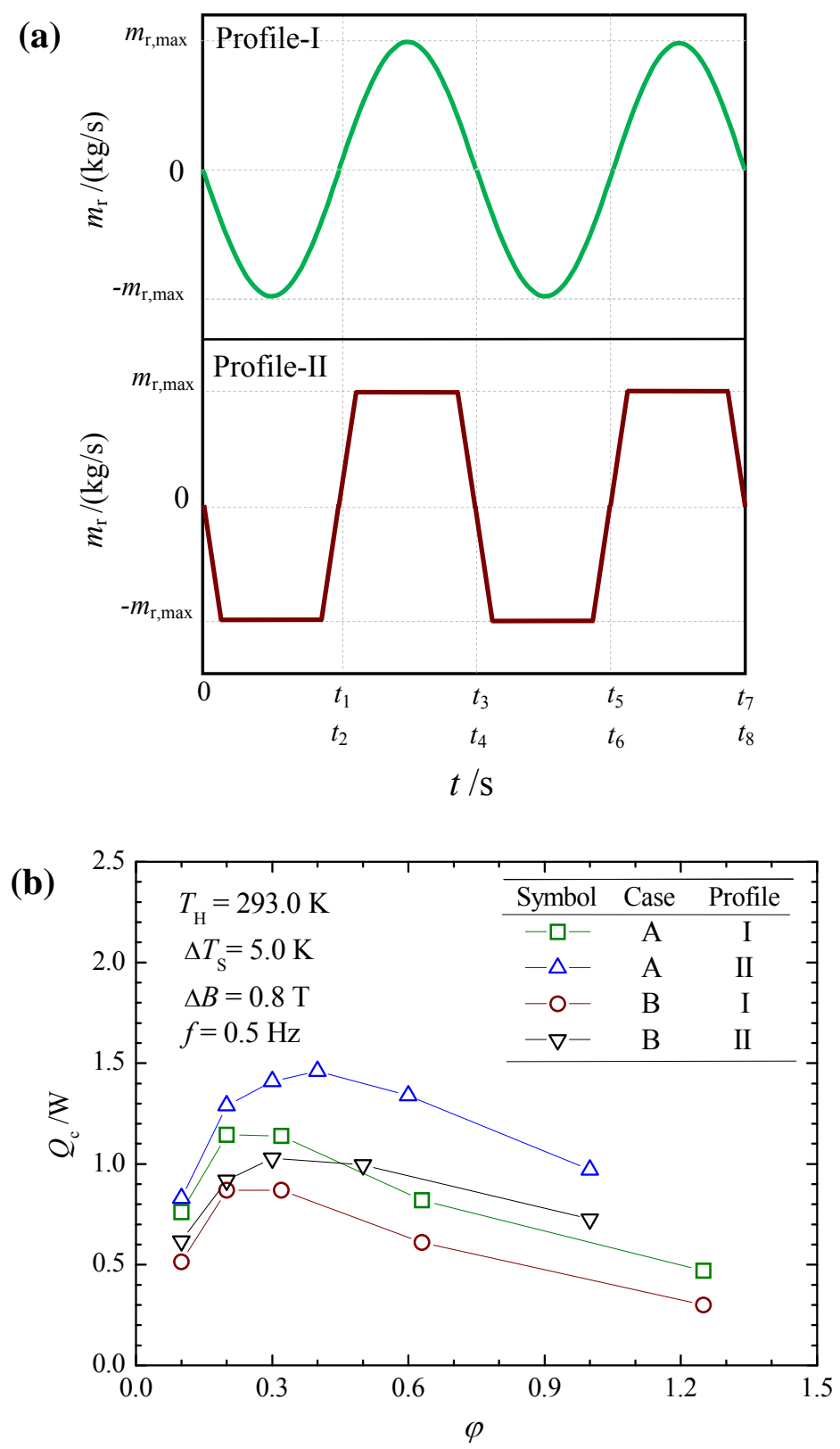

Fig. 19 Effect of mass flow rate profile. (a) two profiles of mass flow rate and (b) variation of cooling capacity with utilization for two profiles of mass flow rate. Microchannel regenerator cases A and B (see Table 6). The solid line is a guide for the eye. 

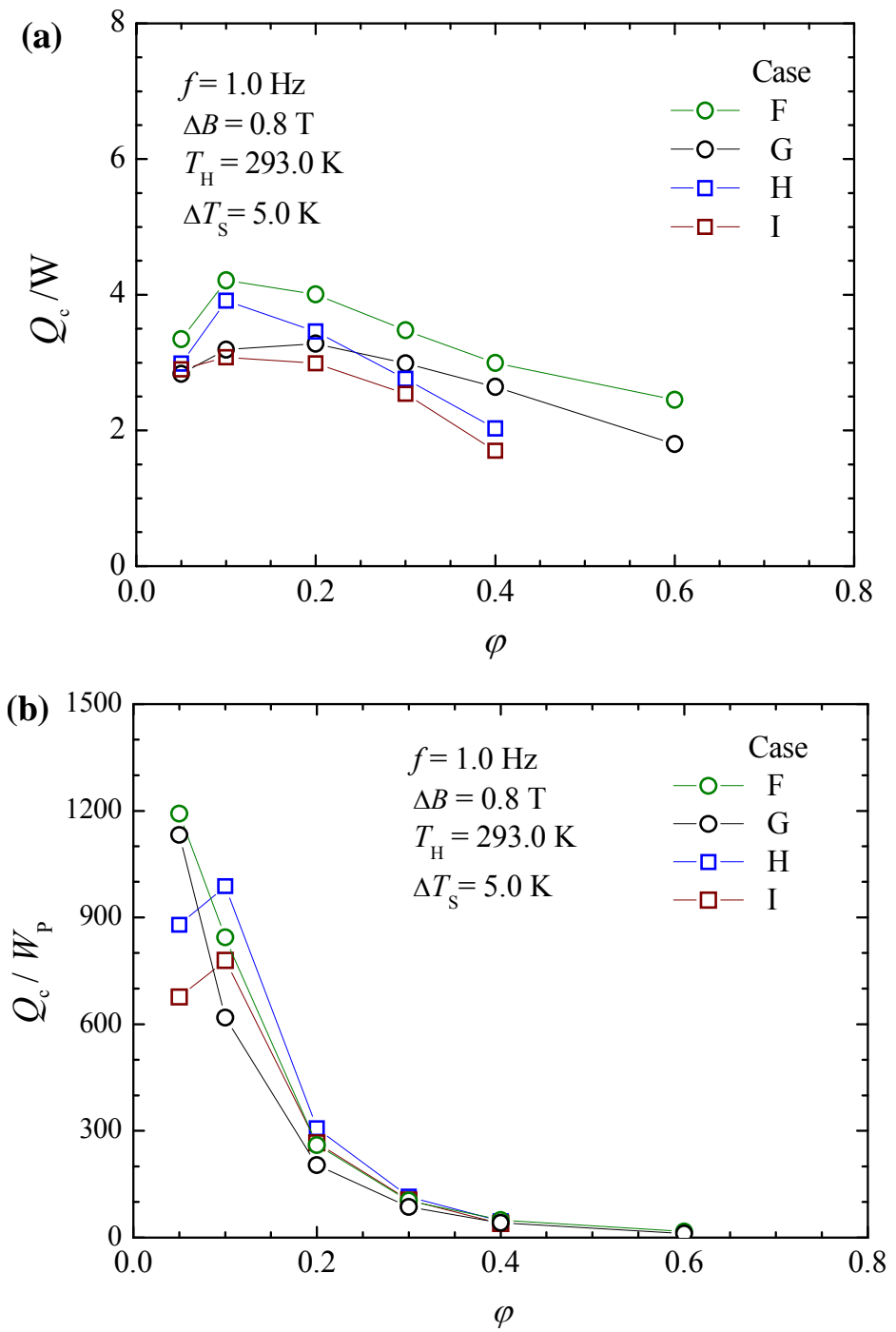

Fig. 20 Comparison of the performance for two microchannel and two parallel-plate regenerators (see Table 6). (a) cooling capacity; (b) cooling capacity per unit pumping power. The solid line is a guide for the eye. 